\title{
Valuation of intergenerational transfers in funded collective pension schemes*
}

\author{
Roy P.M.M. Hoevenaars ${ }^{\dagger} \quad$ Eduard H.M. Ponds ${ }^{\ddagger}$
}

First version: September 19, 2006

This version: March 4, 2007

\begin{abstract}
This paper applies contingent claim analysis to value pension contracts for real-life collective pension plans with intergenerational risk sharing and offering DB-like benefits. We rewrite the balance sheet of such a pension fund as an aggregate of embedded generational options. This implies that a pension fund is a zero-sum game in value terms, so any policy change inevitably leads to value transfers between generations. We explore intergenerational value transfers that may arise from a plan redesign or from changes in funding policy and risk sharing rules. We develop a stochastic framework which accounts for time-varying investment opportunities and computes the embedded generational options. Changes in the values of the generational options enable us to evaluate the impact of policy modifications in the pension contract with respect to intergenerational transfers and redistribution. We find that a switch to a less risky asset mix is beneficial to elderly members at the expense of younger members who lose value. A reallocation of risk bearing from a plan with flexible contributions and fixed benefits to a plan with fixed contributions and flexible benefits leads to value redistribution from older plan members to younger ones.
\end{abstract}

Keywords: Value-based ALM, generational accounting, embedded options, intergenerational risk sharing, funded defined-benefit plans, hybrid plans, public finance, social security reform

JEL classification: G13, G23, H55

\footnotetext{
${ }^{*}$ We thank Michael Brandt, Willem Buiter, Jiajia Cui, Casper van Ewijk, Frank de Jong, Niels Kortleve, Roderick Molenaar, Franz Palm, Peter Schotman and Luis Viceira for their comments on earlier versions of this paper and Roderick Molenaar, Alexander Paulis and Jo Speck for their help in constructing the deflator set and the actuarial set.

${ }^{\dagger}$ Roy Hoevenaars, ABP and Maastricht University, E-mail: r.hoevenaars@ke.unimaas.nl

${ }^{\ddagger}$ Eduard Ponds, ABP and Netspar, E-mail: eduard.ponds@abp.nl.
} 


\section{Introduction}

The introduction of fair value principles in the pension fund industry has had a profound impact, such as the trend to define more explicit pension contracts (Kortleve et al. 2006). Such a contract can be characterized as being transparent and well defined in terms of proceeds and costs for contract holders, and how these contracts' proceeds and costs are related to underlying key variables. Indeed, these types of contracts can be seen as equivalent to financial contracts with embedded options.

An important advantage of explicit and well-defined pension contracts is that contingent claim pricing techniques can be implemented to value them. The first contributions in this field date back to the 1970s, among them classic papers related to company-sponsored defined benefit (DB) pension fund plans, such as Sharpe (1976), and Tepper (1981).

However, DB plans, wherein promised benefits to members are guaranteed and the risks in the funding process are borne primarily by the employer, are being phased out. In the US and UK private sectors, DB plans have largely been replaced by individual defined contribution (DC) plans. Employer-sponsored DB plans also have been replaced by stand-alone pension funds with DB-like benefits, where risks are shared between the younger and older generations of plan members according to explicit rules (Boeri et al. 2006). Many pension funds in the Netherlands have recently taken this route. Also, sector-wide pension funds and public sector pension funds in countries such as Canada, the US and Finland have moved in the direction of stand-alone risk-sharing cooperatives (Ambachtsheer 2007).

The contribution of this paper is to apply contingent claim analysis to the valuation of pension contracts for real-life collective pension plans with intergenerational risk sharing and that offer DB-like benefits. In particular we explore intergenerational value transfers that may result from a plan redesign or from changes in funding policy and risk sharing rules. We develop a stochastic framework which accounts for time-varying investment opportunities and computes embedded generational options. Changes in the value of generational options enable us to evaluate the impact of policy switches in the pension contract with respect to intergenerational transfers and redistribution.

It is well-known from the literature that collectively funded pension schemes with intergenerational risk sharing may be welfare-enhancing ${ }^{1}$. Current and future plan participants are able to share shocks in asset returns and labor income and thereby smooth these shocks over and even beyond the lifespan of any single generation (Cui et al. 2006, Gollier 2006,

\footnotetext{
${ }^{1}$ For a general exposition on the welfare aspects of intergenerational risk sharing, see Gordon \& Varian (1988), and Shiller (1999). Contributions to the extensive literature in the field of pensions can be divided into the categories of risk sharing via "pay-as-you-go" plans (see Merton 1983, Enders \& Lapan 1982, Krueger \& Kubler 2005) and risk sharing via funded plans (see Cui et al. 2006, Gollier 2006).
} 
Teulings \& de Vries 2006). Surpluses or deficits in the funding process are shared between younger and older generations and future generations by adjusting either contributions, benefit levels or a combination of these, which leads to intergenerational transfers. Mandatory participation backed by appropriate government legislation makes this long run smoothing possible as future generations cannot opt out when they are confronted with a low initial level of funding.

An important prerequisite for support for this intergenerational risk-sharing pension plan is that all participants perceive the plan as fair. One could say that a pension plan is fair when the participants are fairly compensated for the risks allocated to them. In financial markets, the no-arbitrage principle guarantees that the market-based compensation for risk taken is fair, such that risk-taking is compensated by an appropriate reward. Within pension funds, the no-arbitrage principle of financial markets is replaced by the rules of the pension contract, which define the risk and reward allocation amongst the members. Essentially, a pension contract defines what is being promised, how the promises are funded (asset mix and contribution policy) and who is bearing the risks in the funding process (risk allocation rules). Real-life pension contracts are usually complex in nature. Badly structured pension contracts may easily result in transfers of wealth when, for individuals or stakeholders, the balance between allocated risk and allocated reward compensation diverges from the riskreward trade-off found in financial markets. Therefore, a pension contract may easily produce hidden transfers of wealth among stakeholders. The use of embedded generational options enables us to detect these value transfers.

This paper innovates in combining three building blocks. The first building block is the field of generational accounting as developed in public finance. We use this method to frame a pension fund in terms of generational accounts. A generational account is defined as the difference between benefits to be received and contributions to be paid by a specific age cohort. The second building block is the valuation of these generational accounts as embedded options with the help of deflators. As the third building block, we employ an asset liability management (ALM) model. ALM has proved its usefulness in its ability to simulate, in a stochastic and integrated framework, the often complex real life cashflow patterns between a pension fund and its stakeholders. The output of the ALM model is used to value the various generational embedded options.

Generational accounting was developed by public finance economists to investigate intergenerational distributional effects of fiscal policy (Auerbach et al. 1999, Kotlikoff 2002). Generational accounting reveals the zero-sum feature of government finance - what some generations receive as an increase in net lifetime income must be paid for by other generations, who will experience a decrease in net lifetime income. Generational accounting is also of relevance for collective pension plans with intergenerational risk sharing. These plans indeed 
can be framed as a zero-sum game as well, implying that changes in the funding strategy or an adjustment in risk allocation rules will lead to intergenerational redistribution (Ponds 2003).

Furthermore, this study is indebted to the literature on framing pension funds in terms of embedded options. Since the classic paper of Sharpe (1976), there has been a large number of applications of contingent claim analyis to real-life problems in the fields of pensions and insurance (Blake 1998, Steenkamp 1999, Chapman et al. 2001, Guillén et al 2006, Kortleve\&Ponds 2006, Kocken 2006). Ponds (2003) was the initial contribution to combining generational accounting with embedded options in order to identify value transfers between generations within pension funds. Using a simple one-period binomial model, he shows that intergenerational value transfers occur when different generations in the pension fund do not get market-based compensation for the risks allocated to them. He calls this approach "valuebased generational accounting." Cui et al. (2006) apply this approach to a multi-period, multi-risk setting for the purpose of analyzing the welfare aspects of intergenerational risk sharing. They show intergenerational risk sharing within a pension fund is indeed a zero-sum game in value terms; however well-structured plans may be a positive-sum game in welfare terms compared with the optimal individual plan without risk sharing. The welfare analysis is performed from the perspective of a new worker aged 25 .

There is a broad literature on asset liability modeling (see Zenios\&Ziemba (2006) for an overview). As in Boender (1997), Bauer et al. (2006) and Boender et al. (2007), we use a scenario approach to asset-liability management. We develop an integral ALM framework with a realistic description of the policy tools available for pension funds in operation regarding asset allocation, indexation policy, and contribution rate setting. The ALM analysis incorporates term structures of risk as in Campbell\&Viceira (2005). The accompanying time-varying investment opportunities are important for long-term institutional investors like pension funds (see Hoevenaars et al. 2005). The modeling framework adapts the pricing kernel and defines an affine term structure of interest rates as in Cochrane\&Piazzesi (2005).

This paper is the first to apply the methodology of embedded generational options to real existing pension funds with intergenerational risk sharing. We explore intergenerational transfers that result from policy changes. These intergenerational value transfers are calculated as changes in the value of embedded generational options resulting from these policy adjustments. We find that any policy change inevitably will lead to value transfers. A switch to a less risky asset mix is beneficial to older plan participants at the expense of the younger members, who lose value. A reallocation of risk from flexible contributions with fixed benefits to fixed contributions with flexible benefits leads to value redistribution from older members to younger ones.

The set up of the paper is as follows. We first discuss the recent trend worldwide of 
reforming the traditional defined benefit plan. The framework of generational accounting is introduced in section 3. Then we explain the method of value-based generational accounting. Section 4 highlights the relevance of value-based ALM. Section 5 describes the methodology of embedded generational options. Section 6 applies the methodology to a stylized pension fund which is representative for a real existing stand-alone multi-member plan. As an illustration we analyze some recent policy reforms in the Netherlands. We close the paper with a discussion of how the proposed method can be applied to other areas, like generational accounting in public finance and reforms in social security.

\section{Pension plan reform}

Pension funds worldwide experienced a serious fall in funding ratios after 2000. This was due in particular to two developments in financial markets - first a fall in stock prices and a corresponding decline in the value of assets held by pension funds, and secondly, a fall in interest rates to historic low levels, which lead to a sharp increase in the fair value of pension fund liabilities. At the same time, fair value accounting principles became the norm in pension fund accounting. The fall in funding ratios could not be masked, as assets and liabilities should be reported on a mark-to-market basis. The new accounting principles based on fair value principles (IFRS) require that companies which provide pension benefit guarantees account the residue of the pension fund on the company balance sheet. In order to prevent pension risks from interfering with core business, companies sought to remove themselves from bearing risks in their pension funds. Furthermore, supervisors strengthened solvency requirements for pension funds.

These developments pushed pension funds to reconsider pension plan design and risk allocation rules. Most pension plans in the postwar period were set up as traditional defined benefit plans, wherein promised benefits to members are guaranteed and the funding risks are absorbed by the employer-sponsor. The response of many private sector pension funds in the UK and in the US was to close defined benefit plans to new entrants. New plan members were offered DC plans. As a consequence, the inherent risks in pension funding are shifted from the employer-sponsor towards the individual members (Munnell 2006).

Another response has been to transform employer-sponsored DB plans into stand-alone multi-member plans where risks are shared among the members. This response implies intergenerational risk sharing as the most important way to absorb the funding risks of a collective plan. Boeri et al. (2006) advocate this type of response. Notably, pension funds in the Netherlands took this route. There was strong resistance to adopting individual DC

plans. Member representatives seek to safeguard the benefits of intergenerational risk sharing and the advantages of a collective plan, such as low costs and professional risk management. 
This paper is oriented toward the analysis of value transfers within stand-alone multi-member plans, where these transfers stem from changes in funding strategy and risk allocation rules.

\section{Generational accounting under uncertainty}

Generational accounting is a method developed by public finance economists as a tool for investigating the intergenerational distributional effects of fiscal policy (Auerbach et al., 1999, Kotlikoff 2002). Generational accounting is based on the government's intertemporal budget constraint, which requires that either current or future generations pay for government spending via taxation. The government's net wealth (including debt) plus the present value of the government's net receipts from all current and future generations, must be sufficient to pay for the present value of the government's current and future consumption. The generational accounting method can be employed for calculating the present value changes in net life-time income of both living and future generations that result from changes in fiscal policy. Generational accounting reveals the zero-sum feature of the intertemporal budget constraint of government finance - what some generations receive as an increase in net lifetime income must be paid for by other generations who will experience a decrease in net lifetime income. Planned increase or decrease in government debt can be used for tax smoothing over time in order to realize a sustainable fiscal policy (Auerbach et al. 1999, van Ewijk et al., 2000).

Similarly, the method of generational accounting may be of use in evaluating the policy of pension funds to cover both current and future participants. Two similarities with public finance can be discerned. Pension funds also face an intertemporal budget constraint, as the promised benefits must be backed by current and future contributions and returns on paid contributions. Secondly, as the government uses the tax instrument to close the budget over time, adjustments in contribution and indexation rates are the instruments used by pension funds to square the balance over time.

Economists using the generational accounting framework for public finance issues find difficulty in dealing with uncertainty (Kotlikoff 2002). Usually, a deterministic approach is followed. Uncertainty is studied using a sensitivity analysis for alternative assumptions for key variables, amongst them the discount factor. However a value-based approach is more appropriate to deal with uncertainty. We rewrite the pension fund in generational accounts and apply the value-based approach. The uncertain cashflows from and to the participating cohorts, in particular contributions and benefits, are treated as embedded generational options which can be valued with the help of stochastic discount factors (see section 5.2). Moreover the value-based approach reveals the zero-sum character of the contract. At any given time, the total economic value to be distributed amongst the generations is equal to the value of pension fund assets. Alternative funding and risk-allocation rules have no impact on 
total economic value, however this may lead to transfers of value between generations.

The generational account approach as applied by public finance economists also has been criticized for the neglect of general equilibrium repecussions of changes in the budgetary policy of the government. Usually tax incidences are ignored as well as impact of policy changes on relative prices (Buiter (1997)). This critique may be of relevance for government studies, however not for this study as the pension fund in operation is sufficiently small to warrant a partial analyis.

\section{Asset Liability Management}

\subsection{Classical ALM}

Pension funds use ALM analysis to evaluate the pension contract in operation and to explore the performance of alternative pension deals. Essentially, a pension contract defines what is being promised, how the promises are funded (asset mix and contribution policy) and who is bearing the risks in the funding process (risk allocation rules). ALM is broadly seen as a cornerstone for the fund policy as it provides insight into the realism and the sustainability of the pension contract in operation over differing horizons. Typically an ALM study uses an economic model to produce stochastic simulations of returns on asset classes and other relevant economic data, like inflation. Subsequently a scenario analysis is performed that results in probability distributions for the key variables. Sensitivity analysis is usually carried out to explore specific policy variants in terms of asset mix, contribution policy and indexation rules. Policy variants are evaluated in terms of expected values and relevant risk measures for key variables - for example, the funding ratio, the contribution rate, the indexation rate, and so on. Moreover one can easily take care of specific constraints, like funding requirements of the supervisor (e.g., a minimum probability of underfunding) and a maximum level of contribution rate.

\subsection{Value-based ALM}

Despite its widespread popularity, one may feel uncomfortable with the classical ALM tool kit. Chapman et al. (2002) characterize ALM studies as producing merely "funnels of doubt", which serve only to demonstrate that taking more risk will imply more uncertainty about key outputs. Moreover, it is difficult to rank policy variants using solely the classical ALM output. Is a risky strategy with, on average, a high but volatile funding ratio to be preferred above a less risky strategy that will end up with, on average, a low funding ratio with little risk? Younger members in a plan with intergenerational risk sharing may prefer a risky strategy that could yield a high pay-out per unit contribution, whereas older 
members will prefer a liability-hedged investment strategy to safeguard pension fund assets in order to reduce benefit risk. Practitioners solve the ranking problem by discovering the policy setting that is most acceptable given the interests of all participants, taking into account all constraints. However in seeking this 'most acceptable' policy variant, the ALM professionals and/or the board of trustees do not usually consider whether the policy variant is fair in economic value terms for all members. In financial markets, the no arbitrage principle guarantees that the market-based compensation for a taken risk is fair, so that risk taking is accompanied by an appropriate reward compensation. Within pension funds, the no arbitrage principle of financial markets is replaced by the rules of the pension contract defining the risk and reward allocation amongst the members. This may easily end up in transfers of value when, for individuals or stakeholders, the balance between allocated risk and allocated reward compensation is not in line with the risk-reward tradeoff found in financial markets.

Contingent claim analysis is fruitful to test for possible value transfers. Restating the highly stylized framework of Sharpe (1976) into a realistic setting results in what is now called value-based ALM (Kortleve \& Ponds 2006). Value-based ALM essentially uses the same output from scenario analysis as classical ALM, however the future outcomes are discounted back to the present with an appropriate risk adjusted discount rate. This is realized by making use of a pricing kernel specification (see section 5.2 for technical details). Valuebased ALM enables us to detect possible transfers of value resulting from policy changes by examining changes in the value of the various embedded generational options.

\section{The pension fund as an aggregate of embedded generational options}

\subsection{Pension fund characteristics}

Before deriving generational accounts in a pension fund setting, it may be useful to describe the specific institutional characteristics of the pension fund. We study generational accounts for a real life pension fund with intergenerational risk sharing. All funding risks must be borne by current and future members of the pension plan. The content of the pension contract is decisive as to how surpluses and deficits in the funding process are allocated amongst participants. Essentially there are three ways to allocate the funding risks amongst the participants: (i) doing nothing by shifting forward in time a position of underfunding or overfunding, i.e. to future participants; (ii) adjusting the contribution rate; or (iii) adjusting the indexation rate.

The fund under study has the following features:

1. Pension Plan: The pension plan is an average-wage plan with indexed liabilities. Work- 
ers acquire for each year of service $2 \%$ of their pensionable wage as new accrued liabilities. The yearly indexation of benefits and accrued liabilities aims to follow the wage growth of the sector; however the actual indexation may be contingent on the financial position of the pension fund.

2. Liabilities: The real value of accrued liabilities is the value of liabilities when full indexation would always be granted as promised. Valuation is based on discounting future benefit cashflows following from the liability structure using the real interest yield curve net of real wage growth. The nominal value of accrued liabilities is the value of liabilities when no indexation would be given at all. The nominal value of accrued liabilities is derived by discounting the future benefit cashflows using the prevailing nominal yield curve. The duration of the indexed liabilities is 19 years (at a real rate of 2\%). Sixty percent of the participants consist of pensioners. The remaining $40 \%$ comprises the (current and future) active members.

3. Funding ratio: The real funding ratio is defined as the ratio of assets over the value of real liabilities, the nominal funding ratio is assets over the value of nominal liabilities.

4. Pension fund residue: The difference between assets and nominal liabilities is called the pension fund residue.

5. Contribution rate: Workers pay yearly contributions out of their wage income in order to fund new accrued liabilities in that year. Total contributions must be equal to the present value of new rights. We make a distinction between two approaches in setting the level of the contribution rate. In line with many real existing pension funds, the pension fund under study makes use of the funding method. This method reflects the notion that in the long run the sum of contributions plus investment proceeds must match the stream of wage-indexed benefits. In this method, the present value of new liabilities is calculated with the expected rate of return on assets net of wage growth as the discount rate. The second method is called the accounting approach which uses as the discount rate the nominal interest rate in the market minus wage growth ${ }^{2}$.

All workers pay the same uniform contribution rate as a percentage of pensionable wages. This implies that young workers pay more contributions than the present value of their new accrued liabilities, whereas older workers contribute less than their new accrued liabilities. Younger workers grow older so that at the end of their careers there will be a balance between the value of paid contributions and the value of accrued liabilities ${ }^{3}$. Apart from the base

\footnotetext{
${ }^{2}$ The term "accounting" reflects that the same discount rate is used as in the fair value reporting standards. In contrast, the funding approach chooses a stable discount factor in order to mitigate contribution rate volatility. This discount factor is used for funding purposes only, not for reporting.

${ }^{3}$ We refer to Hári et al. (2006) for a general analysis of differences in money's worth of participation in a collective scheme due to differences in age, gender and education level.
} 
contribution rate, an additional contribution rate (positive or negative) may be asked in relation to the funding position of the pension fund.

6. Investment policy: We assume a constant mix rebalancing policy in which the investment manager rebalances to fixed asset weights at the end of each year. The investment universe consists of stocks and bonds only.

\subsection{Generational accounts as embedded options}

The value of pension fund assets $A_{t}$ is equal to the value of total pension fund nominal liabilities $L_{t}$ plus the pension fund residue $R_{t}$ :

$$
A_{t}=L_{t}+R_{t}
$$

The balance sheet next period $(t+1)$ expressed in present value terms at $t$ is

$$
A_{t}+V_{t}\left[C_{t+1}\right]-V_{t}\left[P P_{t+1}\right]=V_{t}\left[L_{t+1}\right]+V_{t}\left[R_{t+1}\right]
$$

Inherent to the deflator approach is that the economic value of initial assets plus investments proceeds is equal to initial assets: $V\left[A_{t}\left(1+r_{t+1)}\right]=A_{t}\right.$ with $r_{t+1}$ as rate of return in $t+1$. The term $V_{t}\left[C_{t+1}\right]$ is the economic value at $t$ of contributions $C_{t+1}$ paid in $t+1$ and $V_{t}\left[P P_{t+1}\right]$ is the economic value at $t$ of pension payments $P P_{t+1}$ in $t+1$. The term $V_{t}\left[L_{t+1}\right]$ stands for the economic value of accrued liabilities at the end of period $t+1$, being the sum of the accrued liabilities at the end of period $t$, including indexation minus the liabilities written off in $t+1$, as they have been reserved for pension payments in $t+1$ plus the new accrued liabilities in $t+1$ attributable to one year of additional service of working members. The term $V_{t}\left[R_{t+1}\right]$ is the economic value at $t$ of the pension fund residue at the end of period $t+1, R_{t+1}$.

Using (1), we can rearrange (2) as:

$$
V_{t}\left[L_{t+1}\right]-L_{t}+V_{t}\left[P P_{t+1}\right]-V_{t}\left[C_{t+1}\right]+\left(V_{t}\left[R_{t+1}\right]-R_{t}\right)=0
$$

This expression says that the one year change in the value of liabilities is backed by contributions and by either an increase or a decrease in the pension fund residue. This reflects the zero-sum nature of a pension fund. However, the zero-sum feature does not hold necessarily for the different age cohorts. We can split up expression (3) by age cohort. This results in the expression below:

$$
\Delta G A_{t+1}^{x}=V_{t}\left[L_{t+1}^{x}\right]-L_{t}^{x}+V_{t}\left[P P_{t+1}^{x}\right]-V_{t}\left[C_{t+1}^{x}\right]+\left(V_{t}\left[R_{t+1}^{x}\right]-R_{t}^{x}\right) \neq 0
$$


where $x$ refers to cohort $x$. We call the term $\Delta G A_{t+1}^{x}$ the generational account option of cohort $x$, that is defined as the economic value at $t$ of the change in the generational account of cohort $x$ during $t+1$.

We assume that the pension fund residue can be allocated amongst the cohorts at all times proportionately to each cohorts's stake of nominal liabilities ${ }^{4}$ :

$$
R_{t}^{x}=l_{t}^{x} R_{t}
$$

with

$$
l_{t}^{x}=\frac{L_{t}^{x}}{L_{t}}
$$

Figure 1 displays the relative distribution of nominal liabilities over the cohorts in 2006. The size of $l^{x}$ initially increases with age because cohorts have fulfilled more years of service, and have more accrued liabilities, and because the time value of accrued liabilities increases as the age of retirement nears. The size of $l_{t}^{x}$ will decline in retirement as liabilities gradually are written off with the planned pension payments.

The sum of all generational account options, $\sum_{x \in X} \Delta G A_{t+1}^{x}$, must be necessarily equal to 0 , reflecting that the pension fund is a zero-sum game in value terms:

$$
\sum_{x \in X} \Delta G A_{t+1}^{x}=0
$$

We can split up $\Delta G A^{x}$ into two parts: the so-called net benefit option $N B^{x}$ and the so-called residue option $\Delta R^{x}$ :

$$
\Delta G A_{t+1}^{x}=\underbrace{V_{t}\left[L_{t+1}^{x}\right]-L_{t}^{x}+V_{t}\left[P P_{t+1}^{x}\right]-V_{t}\left[C_{t+1}^{x}\right]}_{N B^{x}}+\underbrace{\left(V_{t}\left[R_{t+1}^{x}\right]-R_{t}^{x}\right)}_{\Delta R^{x}}
$$

The net benefit option consists of the change in the value of liabilities $V_{t}\left[L_{t+1}^{x}\right]-L_{t}^{x}$ due to new nominal accruals and the writing off of planned nominal pension payments, plus the value of actual pension payments $V_{t}\left[P P_{t+1}^{x}\right]$ including indexation, and the value of paid contributions $V_{t}\left[C_{t+1}^{x}\right]$.

The net residue option says that a cohort gives away the certain claim on the current residue $R_{t}^{x}$ by participating in the fund and it receives an uncertain claim on the residue at the end of the evaluation period $R_{t+1}^{x}$, with economic value equal to $V_{t}\left[R_{t+1}^{x}\right]$.

Below, we compare some alternative policy variants to study the impact on the generational accounts of cohorts. This comparison is based on the expression:

$$
\Delta G A_{\text {alternative }}^{x}-\Delta G A_{\text {basic }}^{x}=\left(N B_{\text {alternative }}^{x}-N B_{\text {basic }}^{x}\right)+\left(\Delta R_{\text {alternative }}^{x}-\Delta R_{\text {basic }}^{x}\right) \neq 0
$$

\footnotetext{
${ }^{4}$ The claim on the residue is not just a fictive claim in accounting terms. In the Netherlands, the "system of value transfer" is operative. This system rules that when an employee switches to another pension fund because of a new job, the worker has the right to transfer wealth from the old to the new fund equal to the value of accrued liabilities, including indexation.
} 
Stepping over from the current pension contract to an alternative one may lead to a change of the generational account option of cohort $x$, and this can be split up into changes in the net benefit option and in the residue option held by cohort $x$.

\subsection{Pricing embedded options}

The ALM framework is based on a simulation study which projects the development of the pension fund in many future scenarios. The policy horizon is 20 years $^{5}$. As this paper focuses on the method of value-based generational accounting, we have suppressed the degree of complexity of the ALM framework. The investment universe consists only of a MSCI world stock index and nominal bonds with a constant maturity of 10 years. Furthermore we assume that wage inflation equals price inflation, so that real wage growth is zero ${ }^{6}$.

In accordance with Campbell and Viceira (2002), we describe the return dynamics by a first-order vector autoregressive (VAR) model. The relevant economic factors $z_{t}$ in the model include the short three-month interest rate, the 10-year zero coupon rate, price inflation, stock returns in excess of the three-month interest rate, and the corresponding dividend yield. Returns on a rolling 10-year constant maturity bond portfolio are constructed from the nominal term structure. Formally, the VAR is written as:

$$
z_{t+1}=c+B z_{t}+\Sigma \zeta_{t+1}
$$

where $\zeta_{t+1} \sim N(0, I)$. In order to value the embedded options, we specify the pricing kernel as:

$$
-\log M_{t+1}=\delta_{0}+\delta_{1} z_{t}+\frac{1}{2} \lambda_{t}^{\prime} \lambda_{t}+\lambda_{t}^{\prime} \zeta_{t+1}
$$

where $\lambda_{t}$ are time-varying prices of risk. For further technical details, we refer to Nijman and Koijen (2006), Cochrane and Piazessi (2005) and Ang and Bekaert (2004). Quarterly European data (1973:III-2005:IV) are used to estimate the parameters in the VAR system. MSCI world stock returns and dividend yield are from Factset. German interest rates are from the Deutsche Bundesbank. Summary statistics of the data and scenarios are provided in Table 1. Stochastic scenarios are constructed by forward iterating the VAR. We transform the constant term $(c)$ to impose a different mean on the scenarios. Asset returns are used to

\footnotetext{
${ }^{5}$ An infinite horizon for the pension contract and pension fund would be hard to justify. We choose to evaluate the fund position at a finite horizon. On the one hand, we aim for insights about the implications of a pension policy at various horizons. On the other hand, it makes no sense to simulate too far into the future, because we have only a limited amount of historical data to estimate the return dynamics. A 20 year horizon reveals implications for short, medium and long horizons.

${ }^{6}$ The assumption of a real wage growth of zero avoids the problem of valuation in an incomplete market. As there are no wage-indexed assets, risk relating to real wage growth is not priced into the market. De Jong (2005) discusses several methods to value wage-indexed cashflows in an incomplete market.
} 
determine the returns on the asset mix. Interest rates are used to compute the present value of liabilities, and inflation scenarios are employed to index the liabilities. We use $M_{t+1}$ as the stochastic discount factor for valuation of embedded options in the pension deal.

Our ALM modeling process provides both classical as well as value-based outcomes. The classical results include a set of probability distributions for all relevant ALM output variables in each future year. Asset returns and the asset mix policy are used to determine returns on the asset mix. Real and nominal interest rates are used to compute the present value of liabilities in real and nominal terms, respectively. The inflation scenarios are employed to index the liabilities.

We value embedded options in the pension contract using the pricing kernel specification, which is arbitrage-free and consistent with the VAR return dynamics of the economic environment. In this way, scenario-dependent and thus stochastic discount factors (deflators) are assigned to the scenarios (see Nijman and Koijen (2006), and Brennan and Xia (2002)). Low discount rates are assigned to bad scenarios, whereas high discount rates are assigned to good scenarios. This reflects the prevailing risk aversion in the market which implies that payoffs during bad times are more valuable than payoffs during good times. Multiplication of the future payoffs $k$ periods from now $\left(P_{t+k}\right)$ by the corresponding stochastic discount factor $\left(M_{t+k}^{*}=M_{t+1} M_{t+2} \cdots M_{t+k}\right)$ and averaging over all scenarios gives the current economic value $V_{t}\left[P_{t+k}\right]$ (i.e., the option value) embedded in the pension contract.

$$
V_{t}\left[P_{t+k}\right]=E_{t}\left[M_{t+k}^{*} P_{t+k}\right]
$$

In the empirical part of our model, we compute only the current price, and not the development of the option value along future scenario paths. This prevents us from simulating a new tree-structure in each scenario, which is unattractive from a computational point of view.

\section{Evaluation of pension fund policies}

We apply the methodology of value-based generational accounting to analyze stylized examples of policy changes for a stand-alone pension fund with intergenerational risk sharing. Using value-based generational accounting, we demonstrate that changes in the pension contract may easily lead to sizeable intergenerational value transfers as the allocation of risk amongst stakeholders changes substantially. We evaluate three types of policy changes: pension plan design (section 6.1), investment policy (section 6.2) and the setting of the contribution rate (section 6.3). Finally, since intergenerational risk sharing is a distinguishing feature of Dutch pension funds, we illustrate value-based generational accounting to evaluate recent policy changes in the Netherlands (section 6.4). Empirical results from our analysis, with help from stylized examples, are used to find the set of policy parameters that simultaneously lead to 
an improvement of solvency management, a preservation of benefit levels, and limitation of intergenerational redistribution of value.

\subsection{Pension plan design}

Figure 2 provides four stylized examples of risk bearing in a funded collective scheme with intergenerational risk sharing. Diagram 1 in figure 2 reflects the case of a DB scheme with no risk allocation at all to current members. There is full indexation and a fixed contribution

rate, irrespective of the financial position of the fund. Actually, funding risks are shifted forward in time and hence these risks must be borne by future participants. Diagram 2 is a stylized representation of risk allocation within a traditional DB plan structure, wherein benefits are guaranteed and funding risks are absorbed by flexible contributions. The third diagram reflects the risk-allocation policy in what we have called a hybrid plan. Contribution rate is fixed. All participants take part in bearing risk as this plan makes indexation of all accrued liabilities solvency contingent. This is also the case in the collective $D C$ plan shown in the fourth diagram; however, no cap or minimum is defined in the indexation of accrued benefits.

The horizontal axis in the four diagrams denotes the value of assets $A$. A pension fund is said to be fully funded when assets $A$ equal the value of the real liabilities $L_{R}$, the latter being the value of accrued liabilities when full indexation is always given. $L_{R}$ is calculated by discounting the accrued liabilities with the real yield curve, net of real wage growth. The value of the nominal liabilities, $L_{N}$, is the value of accrued liabilities when no indexation is given. The size of $L_{N}$ is determined by discounting the accrued liabilities with the nominal yield curve. The difference between real and nominal liabilities, $L_{R}-L_{N}$ is the required indexation reserve that is needed to meet the promise of full indexation to plan participants. The actual indexation reserve position is $A-L_{N}$ and it may be either positive or negative.

Along the vertical axis, the contribution rate and the indexation rate are set.

\subsubsection{No risk allocation}

No risk management implies that there is always full indexation where the indexation rate $i_{t}$ is equal to the wage growth rate $\pi_{t}$ and the contribution rate $P_{t}$ is always equal to the base contribution rate $P^{*}$ :

$$
\begin{gathered}
P_{t}=P^{*} \\
i_{t}=\pi_{t}
\end{gathered}
$$




\subsubsection{Traditional DB plan}

In the traditional DB plan, displayed in diagram 2, the indexation rate $i_{t}$ is always equal to the wage growth rate $\pi_{t}$ and funding risk is borne by the workers by means of adjustments in the contribution rate. The contribution rate $P_{t}$ comprises two components: the base contribution rate $P^{*}$ and the additional contribution rate $P_{t}^{a d d}$ as follows:

$$
\begin{gathered}
P_{t}=P^{*}+P_{t}^{a d d} \\
i_{t}=\pi_{t}
\end{gathered}
$$

where

$$
P_{t}^{a d d}=\frac{L_{t}^{R}-A_{t}}{P \text { V35yearPensionableWages }}
$$

Additional contributions are not necessary when assets $A_{t}$ match real liabilities $L_{t}^{R}$. A situation of real underfunding, $A_{t}<L_{t}^{R}$, or real overfunding, $A_{t}>L_{t}^{R}$, leads to a surcharge, or to a cut in the contribution rate, respectively. A situation of underfunding or overfunding is smoothed out over a period of 35 years. This is captured in the expression above by the term in the denominator, reflecting the present value of pensionable wages in the coming 35 years.

\subsubsection{Hybrid plan}

The contribution rate in the hybrid plan is stable and independent of the financial position of the fund. There is room for full indexation equal to wage growth when the value of assets is equal to or larger than the value of the real liabilities, $A_{t} \geq L_{t}^{R}$. Then the actual indexation reserve $A_{t}-L_{t}^{N}$ is at least equal to the required indexation reserve $L_{t}^{R}-L_{t}^{N}$. The indexation rate will be zero when assets are equal to or even below nominal liabilities, $A_{t} \leq L_{t}^{N}$. The actual indexation reserve is then zero or even negative. Between these two points, i.e. when $L_{t}^{N}<A_{t}<L_{t}^{R}$, indexation follows wage growth partly where the given indexation is determined by the proportion of actual indexation reserve in relation to the required indexation reserve, as follows:

$$
\begin{gathered}
P_{t}=P^{*} \\
i_{t}=\alpha_{t} \pi_{t}
\end{gathered}
$$

where

$$
0 \leqq\left(\alpha_{t}=\frac{A_{t}-L_{t}^{N}}{L_{t}^{R}-L_{t}^{N}}\right) \leqq 1
$$


When assets exceed the value of indexed liabilities, there is room to provide extra indexation until there is a full catching-up of any previously missed indexation. This is reflected in diagram 3 by the dotted line.

\subsubsection{Collective DC plan}

The collective DC plan can be seen as the counterpart of the traditional DB plan regarding risk allocation. The contribution rate is set at the level of the base contribution rate, and no additional contributions are asked. Management of solvency risk is run via the indexation rate, where the yearly indexation is proportional to the funding position. Neither a cap nor a floor is applied to the indexation rate. The reference variable for the indexation rate is still wage growth. However, any funding shortage or surplus will lead to a relative adjustment in the indexation rate vis-a-vis the wage growth rate. Full indexation equal to wage growth $\pi_{t}$ is given when $A_{t}=L_{t}^{R}$; this is when the actual indexation reserve matches the required indexation reserve rate. No indexation is given when the actual indexation reserve position is zero: $A_{t}=L_{t}^{N}$.

$$
\begin{gathered}
P_{t}=P^{*} \\
i_{t}=\alpha_{t} \pi_{t}
\end{gathered}
$$

where

$$
\alpha_{t}=\frac{A_{t}-L_{t}^{N}}{L_{t}^{R}-L_{t}^{N}}
$$

\subsubsection{Results - pension reforms and risk allocation}

We apply a classic ALM study 20 years ahead and evaluate the results using value-based generational accounting. The asset mix for the four variants of pension plan design is composed of $50 \%$ stocks and $50 \%$ bonds. The expected real rate of return of assets for this mix is $4,5 \%$, so the outcome for the base contribution rate $P^{*}$ is $17 \%$ of pensionable wage income. We set the initial real funding ratio at $85 \%^{7}$, reflecting the current underfunding of many pension plans.

The classic ALM results for the four variants of plan design are summarized in Table 2, columns (1) to (4). The text below the table explains the indicators.

The expected funding ratio after 20 years for all four variants improves strongly, as shown by the mean and the median at the end of the evaluation horizon, which reach values above $100 \%$. The mismatch risk for a 50-50 mix for the four variants is slightly higher than $8 \%$. The variants differ in how this mismatch risk is absorbed. The DB variant with no risk absorption

\footnotetext{
${ }^{7}$ For the stylized pension fund, this implies a nominal funding ratio of $120 \%$. A nominal funding ratio of about $140 \%$ corresponds with a real funding ratio of $100 \%$.
} 
by current members implies that risk is shifted forward in time to future members. This variant has the highest spread in funding ratio as measured by the standard deviation and the within probability of underfunding. The traditional DB variant absorbs the mismatch risk by adjusting the contribution rate in order to restore a situation of underfunding or overfunding. This results in a high volatility for the contribution rate. The average year-toyear change in the contribution rate is $3.3 \%$-point. The funding ratio risk and probability of underfunding are reduced strongly due to the flexible contribution rate.

The hybrid plan and collective DC variants absorb mismatch risk via indexation adjustment. The hybrid plan imposes a cap (full indexation) and a floor (zero indexation) in indexation adjustments. But the collective DC variant has no restrictions regarding the actual indexation rate. This explains why the hybrid plan shows more spread in the funding ratio compared with the collective DC variant (compare standard deviation funding ratios, $22 \%$ and $16 \%$ respectively, and the within probability of nominal underfunding, $5 \%$ and $4 \%$ respectively), whereas the collective DC variant has more volatility in the indexation ratio. The standard deviation for the indexation ratio is $13 \%$ for the hybrid plan and $28 \%$ for the collective DC variant, and the probability of a cumulative indexation ratio of less than $80 \%$ is, for the hybrid plan 15\%, and is $31 \%$ for the collective DC plan. However the collective DC plan delivers the highest median and mean for the yearly indexation ratio. The median and the mean of the indexation ratio are $101 \%$ and $106 \%$, respectively, for the collective DC plan, whereas the hybrid plan has the significantly lower values of $91 \%$ and $79 \%$ respectively.

Now we turn to analysis in value terms. Table 3 reports the residue option at the end of the 20-year period. The residue option $V_{t}\left[R_{t, k}\right]$ can be split up into a surplus option value $V_{t}\left[S_{t, k}\right]$ and a deficit option value $V_{t}\left[D_{t, k}\right]$, both with nominal liabilities as "exercise price". The surplus option is a European call option on the surplus for the participants written by the fund. The deficit option can be seen as the economic value of a European put option written by the plan's members.

$$
\begin{aligned}
V_{t}\left[R_{t, k}\right] & =E_{t}\left[M_{t+k}^{*}\left(A_{t+k}-L_{t+k}^{N}\right)\right] \\
& =E_{t}\left[M_{t+k}^{*} \max \left(0, A_{t+k}-L_{t+k}^{N}\right)\right]+E_{t}\left[M_{t+k}^{*} \min \left(0, A_{t+k}-L_{t+k}^{N}\right)\right] \\
& =V_{t}\left[S_{t, k}\right]-V_{t}\left[D_{t, k}\right]
\end{aligned}
$$

Columns (1) through (4) report the options related to the end value of the residue for the four pension plan variants. All variants start with a residue of $20 \%$ of nominal liabilities in 2006. The value of the residue at the end of the 20-year horizon shrinks in the no risk management plan to $1 \%$. The difference between the surplus and deficit options is more than $32 \%$ and this difference is the largest of the four variants, as in this variant there is no risk absorption through adjustments in contributions or benefits. The use of a flexible contribution rate in the traditional DB plan reduces the spread between these two option 
premiums to $25 \%$. Moreover the value of the residue option is increased considerably, by more than $16 \%$ to $17 \%$, the result of an increase in the surplus option $4 \%$ and a decrease in the deficit option by $11 \%$. Note also that the spread in option premiums can be further reduced if the pension fund were to convert to the hybrid plan. The spread is reduced even more in the collective DC plan. Furthermore, note that conversion to the hybrid plan and the collective DC plan is associated with a further improvement in the residue option.

Our stylized example suggests that value transfers between generations are larger in a traditional DB plan than they are in a hybrid plan. Figure 3 shows the outcome for the generational account options held by the various cohorts over the 20 -year evaluation period for the traditional DB plan and the hybrid plan. The horizontal axis shows the age of the cohorts at the start of the evaluation period. The oldest cohort is aged 105 and this cohort will die with certainty within 1 year. The youngest cohort (-2) will be born within two years from now. At the end of the 20-year evaluation period, these future participants will be 18 and will join the labor force.

Figure 3 shows that the generational account options for the younger workers are negative, whereas the older generation of workers and retirees have a positive generational account option. The differing results for young and older workers can be explained primarily by the levying of a uniform contribution rate, whereas the value of newly accrued liabilities varies with age. The value of new liabilities is lowest for the youngest worker and highest for the oldest worker. This is the main reason why the young have negative generational account options, and older workers have positive generational account options. In this paper, we take the practice of a uniform contribution rate and the implied redistribution from younger to older workers as given. The focus in this paper is to evaluate the change in embedded options held by the various cohorts due to changes in pension fund policy regarding pension plan design, investment policy and the setting of the contribution rate level. These changes in embedded options will also occur when the practice of uniform contribution rate is abolished and every worker pays a contribution sum each year that exactly matches the value of new accrued liabilities in that year.

The retirees have a positive generational account option. In the traditional DB plan, they will receive full indexed pension payments, whereas the initial position of the pension fund is a situation of real underfunding. This also explains why the generational account option for retirees in the hybrid plan is lower as they must accept indexation cuts as long as there is a situation of real underfunding.

Table 4 also clarifies that the move from a traditional DB plan to a hybrid plan will lead to a considerable redistribution of value from older members to younger members. We can calculate the size of generational transfers by using the following expression, which is based 
on expression (9), where the term $G T$ reflects the size of generational transfers,

$$
G T=\frac{\sum_{x}\left|\Delta G A_{\text {hybrid }}^{x}-\Delta G A_{\text {tradDB }}^{x}\right|}{2}
$$

The size of generational transfers amounts to $8.8 \%$ of nominal liabilities in 2006 . This is a large result. We can also calculate the impact in value terms for the different cohorts. For a 60-year old participant, the loss in value due to the conversion to the hybrid plan is equal to almost $7 \%$ of the expected stream of full indexed benefits to be received during retirement or, stated alternatively, approximately $65 \%$ of the average pensionable wage income in the industry. The value gain for the cohort around the age of 25 is of similar size.

In the remainder of this section, we explore in detail how changes in pension plan design influence the embedded options held by the various age cohorts. To this end, we decompose changes in the generational account options into changes in the underlying net benefit options and residue options as demonstrated in expression (8). The figures below display the change in embedded options for each cohort when the traditional DB plan is replaced by the hybrid plan (Figure 4) and when the hybrid plan is replaced by the collective DC plan (Figure 5).

The replacement of the traditional DB plan by the hybrid plan (Figure 4) would imply that the residue option for all cohorts increases, reflecting the improvement of the residue option for the pension fund as a whole. The impact on the net benefit option differs considerably between young and old plan members. This option improves strongly for the younger workers, whereas the older workers must accept a severe deterioration. Note also that the net benefit option for the retirees decreases. All workers will benefit from the replacement of the flexible contribution rate in the traditional DB plan by the fixed contribution rate in the hybrid plan. Workers no longer lose value due to contribution increases in bad times. The introduction of the hybrid plan implies that an unconditional indexation policy is replaced by a conditional indexation policy. All members lose value from this change in indexation policy. Typically, indexation cuts will occur in bad times and these cuts will then be very valuable. Catch-up indexation is provided in good times when the funding ratio is high; however, this additional indexation in good times is not as valuable in value terms. The changes in net benefit options are negative from the age of 43 onwards. Hence for workers older than 43 , the loss in value due to a conversion to a conditional indexation policy more than outweighs the gain in value attributable to a conversion to a fixed contribution rate policy. For workers younger than 43, the contribution impact on the net benefit option is more valuable than the indexation itself.

The replacement of the hybrid plan by the collective DC plan (Figure 5) implies relatively minor effects on the generational account options held by the various age cohorts compared with the effects of replacing a traditional DB plan by a hybrid plan. The effects are in line with expectations. The net benefit options decrease for all cohorts. They all lose value as 
there is no longer a boundary on indexation cuts. Now even negative indexation is possible; this will typically occur in very bad times and hence will have a high value. From the classical ALM results, we have seen that the collective DC plan provides an average indexation ratio larger than $100 \%$ when a full indexation policy is followed. However, high levels of indexation will typically occur in good times and therefore have a low value. On balance, the loss in value due to low or even negative indexation more than outweighs the gain in value resulting from high indexation. The counterpart of the decrease in net benefit options is that the residue options improve.

\subsection{Investment policy in the hybrid plan}

The various plans have up to now been evaluated using an asset mix of $50 \%$ bonds and $50 \%$ equities. Now we examine the impact on the hybrid plan of moving the asset mix toward $100 \%$ bonds or $100 \%$ equities, respectively.

In setting the contribution rate, it is common practice for pension funds to follow a funding approach of taking into account the expected rate of return on assets, net of expected indexation costs. This practice is justified by the notion that, in the long run, the sum of contributions and investment proceeds must match the stream of future indexed benefits; moreover a fixed discount rate mitigates contribution rate volatility. More risk taking therefore warrants a lower contribution rate. An important question, however, arises as to who is bearing the additional risk? When retirees bear part of the additional risk because their indexation is contingent on the financial position of the pension fund, then value transfers will inevitably occur from retirees to workers.

Columns (4), (5), and (6) of Table 2 report the classic ALM results for the hybrid plan with a $50 \%-50 \%$ asset mix, a $100 \%$ equity mix, and a 100\% bonds strategy. The lower rate of return of the $100 \%$ bonds strategy implies an increase in the contribution rate from $17 \%$ to $22 \%$ of pensionable wages. The contribution rate in the $100 \%$ equity strategy is lowered to $14 \%$ of pensionable wages.

The expected real funding ratio of the $100 \%$ equity strategy improves strongly. The initial funding ratio is $85 \%$ and the median and mean of the funding ratio at the end of evaluation horizon are $112 \%$ and $125 \%$, respectively. This strategy implies a high level of risk. The mismatch risk is almost doubled and the within probability of nominal underfunding indicates that half of the scenarios have at least one year of nominal underfunding. Despite the higher average funding ratio, the mean of the indexation ratio declines in comparison with the outcome of the 50\%-50\% strategy, whereas its volatility increases sharply.

The $100 \%$ bonds strategy involves a slow, but gradual path of recovery of the funding ratio from its initial level of $85 \%$ to the aimed-for $100 \%$ real funding ratio. This mix implies a 
low mismatch risk exposure. The within probability of nominal underfunding of this strategy is near zero. Furthermore, note that the expected indexation ratio is almost equal to that of the $100 \%$ equity strategy; however, the associated risk is much lower. So, the $100 \%$ bonds strategy involves much higher certainty around key variables; however, this comes at the price of higher contributions.

Once again we approach the value-based analysis with a comment on the changes in the residue option for the pension fund as a whole (see columns (5) and (6) of Table 3). There is a notable and heavy decline in the residue option when the asset mix is switched to $100 \%$ equities. This switch will indeed lead to a high mean for the funding ratio; however, downside risk is increased as well. In value terms, the additional downside risk outweighs the additional upside risk, and this is reflected in a larger increase in the deficit option compared with the increase in the surplus option. The difference between these two options explains the decline in the residue option itself. The $100 \%$ bonds strategy leads to the elimination of nominal underfunding; the deficit option therefore falls to zero. The residue option equals the surplus option as assets are always larger than the "exercise price" of nominal liabilities.

Figure 6 shows the generational account options for the three investment strategies. Clearly, younger members are winners in value terms with a switch to a $100 \%$ equity strategy, whereas older members benefit from a switch to a 100\% bonds strategy. Figures 7 and 8 display the changes in the generational account options for each cohort and its components, taking the hybrid plan with a 50-50 mix as the benchmark.

The $100 \%$ equities strategy leads to a lower contribution rate and this is beneficial to all workers, leading to an increase in their net benefit options. However, this strategy makes the funding ratio more volatile and so indexation risk is increased. This implies a deterioration of the net benefit option for all retired workers. For workers younger than 54, the positive impact of lower contributions on the net benefit option is larger than the negative impact of more volatile indexation. Older workers and retirees experience a loss in their net benefit option. The $100 \%$ equity strategy makes the funding ratio at the end of the plan horizon more volatile, so the uncertainty regarding full backup of liabilities by assets is increased. Hence, all members lose value and they must accept a decrease in the residue option. The net result of the changes in the two options is that younger workers gain value whereas workers older than 43 and retirees lose value.

The $100 \%$ bonds strategy is the mirror image of the $100 \%$ equity strategy. Workers lose value as the contribution rate is increased. All members gain value due to less uncertainty around indexation, reflected by an increase in member residue options as future residue is characterized by low volatility. In this scenario, workers from the age of 43 onwards and retirees are, on balance, winners, whereas younger workers lose value. 


\subsection{Base contribution rate in the hybrid plan}

Thus far, we have determined the base contribution rate by using the funding approach. For the discount factor in determining the contribution rate, we use the difference between expected rate of return on assets minus the expected growth rate of wages. However, this method is subject to scrutiny as it implies a break between reward taking and risk taking. Current workers are rewarded by more risk taking by a lowering of their base contribution rate, whereas the associated additional risk is transferred to future participants. Bader \& Gold (2002) amongst others, postulated that the base contribution rate must be settled using a fair value accounting basis. Contributions must equal the fair value of new accrued liabilities. This approach - which we will call "the accounting approach" - implies that the contribution rate for an indexed plan must be based on the rate of interest rather than the rate of return on assets.

For the hybrid plan with a 50-50 mix, we compare the results of classic ALM output of the funding approach and the accounting approach. Compare columns (4) and (7) of Table 2. The base contribution rate increases from $17 \%$ to $22 \%$ when the funding approach is replaced by the fair value approach. Higher contributions lead to an improvement in the solvency position and the indexation result. The improvement of the solvency position is also evident in Table 3. The residue option increases from $20 \%$ to $28 \%$ of the initial value of nominal liabilities.

Figure 9 delineates the changes in the embedded options. All participants see an increase in their residue options. Furthermore, retirees and near-retirees see an improvement in their net benefit options as higher contributions lead to a higher funding ratio and hence, higher indexation. Workers younger than 55 see a decrease in their net benefit options as the value loss due to higher contributions eclipses the value gain from higher indexation results. On balance, workers younger than 40 lose value while participants older than 40 gain value. 


\subsection{Evaluation of reform by Dutch pension funds}

Pension funds in the Netherlands play a very large role in providing retirement income ${ }^{8}$. In the postwar period - up to the beginning of the 21st century — pension plans were predominantly employer-sponsored, wage-indexed benefit plans with funding risks primarily borne by the employer. As a result of the pension crisis in the years after 2000, employers increasingly withdrew themselves from the role of risk-bearing party in pension funds. As there was strong resistance among members against switching to individual DC plans, pension funds transformed the employer-sponsored defined benefit plans into stand-alone, multi-member plans based on intergenerational risk sharing. They also reconsidered the nature of the pension plan. The traditional DB plan structure with flexible contributions and fixed benefits was no longer seen as an appropriate model for managing the solvency position. The everincreasing degree of maturity of Dutch pension funds made the steering instrument of flexible contributions highly ineffective ${ }^{9}$. The boards of trustees of many pension funds aimed to reform the traditional DB plan structure in such a way that the following three goals could be realized simultaneously: [1] improvement of solvency risk management; [2] preservation of acceptable pension results; and [3] avoiding intergenerational value transfers resulting from plan redesign as much as possible.

Pension funds introduced the hybrid plan structure, with flexible indexation and fixed contribution rate as the primary method to enhance solvency risk management. The evidence from stylized examples has clarified that this reform indeed leads to some improvement in solvency risk management, however it comes at the price of a considerable reallocation of value from older to younger members (compare Figures 4 and 5).

\footnotetext{
${ }^{8}$ The Dutch pension fund system is very sizeable. It covers more than $90 \%$ of the labor force. The value of assets under management at year-end 2005 was 625 billion euros - $125 \%$ of national income. There are 80 pension funds operating across all industries accounting for two-thirds of assets and plan participants. An additional 600 company pension funds encompass the remainder of assets and plan participants. Employee participation is mandatory and this is governed via collective labor agreements. Most pension funds (more than $95 \%$ ) operate an indexed defined-benefit plan with indexation conditioned on the funding position of the fund. The aim of most plans is to deliver a supplementary pension income above the flat-rate public pension (payg) such that the sum of the public pension and the pension-fund pension is equal to $80 \%$ of average wage income. There is a broad discussion in the Netherlands regarding the degree of collective funding and risk sharing in pension funds. In particular, company pension funds are increasingly exploring introduction of defined contribution elements into their pension plans.

${ }^{9}$ Pension funds in the Netherlands have been operative since the 1950s. The ratio of accrued liabilities over wages for a typical fund has now risen to approximately 5 and it is foreseen that this ratio will increase further. Given a maturity ratio of 5 , the absorption of a $1 \%$ drop in the funding ratio would require a $5 \%$ increase in the contribution rate. Restoration of the funding ratio to a higher level would then require huge additional contribution payments, that would erode the purchasing power of workers. A solution was found in the use of cuts to the year-to-year indexation of accued liabilities. A $1 \%$ increase in funding ratio would require an indexation cut of $1 \%$ applied to all accrued liabilities.
} 
Table 4 indicates the magnitude of intergenerational value transfer when the traditional DB plan is replaced by the stylized examples of pension reform discussed above. The move to a hybrid plan with a 50-50 asset mix and the associated fixing of the contribution rate based on funding principles would imply a value redistribution of $8.8 \%$ over the 20 -year period of evaluation, as discussed in section 6.2.6. The largest redistribution occurs when stepping over to a hybrid plan with a $100 \%$ equity mix. A hybrid plan with a $100 \%$ bonds asset mix leads to a maximum intergenerational transfer of $4.9 \%$, as downside risk is reduced significantly due to the combined effects of workers paying more contributions and the decrease in mismatch risk. However this variant may be unattractive for workers as they must pay higher contributions and accept a deterioration of the pension result vis-a-vis the pension result in the hybrid plan with a 50-50 asset strategy (compare Table 2). Nevertheless, the hybrid plan would justify a higher contribution level than the traditional DB plan. Contributions in the hybrid plan are no longer applied to risk bearing, so there is no reason why workers could lay claim on the rewards of risk taking. Hence, any motivation for using the expected rate of return on assets to set the contribution rate no longer exists. This would validate the replacement of the funding approach by the fair value approach in setting the contribution rate. The contribution rate in the accounting approach is based on the real rate of interest. Application of the fair value approach implies higher paid contributions that will match the fair value of newly accrued liabilities, so there would be no subsidizing of contribution payments by workers.

A pension fund necessarily must be oriented toward finding the "most acceptable" policy mix with respect to the interests of its various constituent groups. Combining the hybrid plan and a 50-50 mix with the fair value approach in setting the contribution rate may be an acceptable midway position amongst the possible variants. Intergenerational value transfer is $5.9 \%$ and of limited size, downside risk as measured by the deficit option (Table 3 ) is low and the pension result, as measured by the outcomes for the indexation ratio, is relatively good (Table 2).

The actual pension reform experience of Dutch pension funds is very close to our reformulation of policy parameters.

\section{Other applications}

The value-based generational accounting method is applied to a real existing industry pension fund. However the method is broadly applicable to the evaluation of any institutional arrangement which implies intergenerational redistribution and risk-sharing. Such arrangements typically can be found in government policies related to fiscal policy and debt management, social security, and health care (Bohn 2005). The particular mix of tax, pension and health care policies is decisive on how costs, benefits and associated risks are distributed 
amongst age cohorts. Value-based generational accounting may be helpful in assessing the fairness of government programs and in preventing excessive intergenerational value transfers. We discuss some specific applications below.

\subsection{Public Finance}

Generational accounting stems originally from public finance with the pioneering work of Auerbach and Kotlikoff (cf. Auerbach et al. 1999). Usually, generational accounting studies are performed in a deterministic setting. However, future projections of tax revenues and government outlays are subject to uncertainty. Generational accounts typically use a real rate of discount that exceeds the real government short-term rate, to adjust for the relative risk of future cash-flows. Sensitivity analysis for various discount rates can be carried out to analyze the impact on generational accounts of different degrees of risk. However this approach disregards the differences in relative risk of government cash flows. As the relative risk of tax income, spending and transfer payments differ, the theoretically appropriate riskadjusted rates at which to discount these flows would also differ, and so will the impact on generational accounts. Kotlikoff (2002) notes that the size of these risk-adjustments in generational accounting remains a topic for future research. We think the use of a stochastic framework and value-based pricing with a specification of macroeconomic risks (productivity, real income growth) and financial market risks (term structure of interest rates, asset pricing) would improve generational accounting in the field of public finance.

\subsection{Social security reform}

Many countries have initiated conversion programs for unfunded defined social security schemes into privatized funded defined contribution schemes (cf. Chile and other countries in Latin America, countries in Eastern Europe, United Kingdom), whereas the US (Feldstein 2005) and many other countries are considering implementation of a conversion program. Such a conversion program implies either a transition burden to be absorbed either by reduced benefits and tax increases or by replacement of implicit pay-as-you-go debt by explicit government debt. Moreover, the conversion programs often are accompanied by minimum return guarantees regarding the defined contribution results. Smetters (2002) values minimum benefit guarantees in proposals to privatize the US Social Security system and finds that the system's guarantees are very costly despite their low probability. When risks, guarantees and costs are not gauged accurately, social security reforms may easily lead to unintended hidden value transfers between generations. Value-based generational accounting may prove helpful by safeguarding that undesired value transfers due to mis-specified design of reform programs will not occur. 


\section{Conclusions}

This paper aims to demonstrate the usefulness of value-based generational accounting for pension funds with intergenerational risk sharing. Value-based generational accounting is useful to control for the intergenerational value transfers that may arise as an inevitable by-product of policy changes. These transfers can be analyzed with the help of changes in the values of the various embedded generational options held by the participants. We have characterized the value-based approach as supplementary to the classic ALM tool kit, which is already used intensively by pension funds in decision-making on pension fund policy. Classic ALM evaluates the performance of alternative pension contracts in terms of expected results and risk measures for key variables like the funding ratio, the contribution rate, and pension benefits.

A number of stylized examples of policy changes in risk allocation, investment policy and the setting of the base contribution rate have been analyzed. We calculate intergenerational value transfers as changes in the values of embedded options resulting from these policy adjustments. We find that any policy change will inevitably lead to value transfers. A more risky asset mix is beneficial to younger members at the expense of older members, who lose value. A reallocation of risk bearing from flexible contributions to flexible benefits also leads to value redistribution from old to young.

Faced by a solvency crisis after 2000, Dutch pension funds were forced by the supervisor to modify their pension contracts, in operation since the 1950s, in order to improve solvency management. Many pension funds replaced the traditional DB plan structure consisting of fixed benefits and flexible contributions by a hybrid pension plan structure with fixed contributions and solvency-contingent indexation. Results from the stylized examples are used to evaluate the recent reforms by Dutch pension funds. We have argued in this paper that an optimal pension deal cannot be defined, as a pension fund is a structure of interests of various stakeholders. A pension fund therefore is oriented at finding the "most acceptable" policy mix. Combining the hybrid plan and a 50-50 mix with the fair value approach in setting the contribution rate may be an acceptable midway position amongst the alternatives. Intergenerational value transfers are of limited size, downside risk, as measured by the deficit option of the funding residue is low, and the pension result, as measured by the outcomes for the indexation ratio, are relatively good. The actual reforms of many Dutch pension funds are very close to this reset of policy parameters.

We see value-based generational accounting as an important extension of the tool kit of decision making for pension funds with intergenerational risk sharing. This method is also useful in evaluating any institutional arrangement which implies intergenerational transfers, like public finance and reforms in social security systems. 


\section{References}

[1] Ambachtsheer K.A. (2007): 'Pension Revolution, A Solution to the Pensions Crisis', John Wiley \& Sons, Hoboken.

[2] Ang A. and Bekaert G. (2004): 'The term structure of real rates and expected inflation', working paper, Columbia Business School.

[3] Auerbach, A.J., Kotlikoff, L.J., and Leibfritz, W. (eds) (1999), 'Generational Accounting around the World', NBER. Chicago, Chicago University Press.

[4] Bader, L. N. and Gold, J. (2002): 'Reinventing pension actuarial science ', working paper.

[5] Bauer, R., Hoevenaars R., and Steenkamp T. (2006), 'Asset Liability Management', Oxford University Press, The Oxford Handbook of Pensions and Retirement Income, Editors: G.L. Clark, A.H. Munnell and J.M. Orszag.

[6] Bohn H. (2005): 'Who bears what risk? An intergenerational perspective', working paper University of California at Santa Barbara.

[7] Blake D. (1998): 'Pension schemes as options on pension fund assets: implications for pension fund management 'in: Insurance: Mathematics and Economics, vol. 23, pp. 263-286.

[8] Boender C.G.E. (1997), 'A Hybrid Simulation/Optimization Scenario Model for AssetLiability Management', European Journal of Operations Research, 99, 126-135.

[9] Boender C., Dert C., Heemskerk F., Hoek H. (2007), 'A Scenario Approach of ALM ', in: Zenios S.A. \& Ziemba T.Z. (2007)

[10] Boeri T., Bovenberg L., Coeré B. \& Roberts A. (2006): 'Dealing with new giants: rethinking the role of pension funds', Geneva Reports on the World Economy 8.

[11] Brennan, M.J., and Xia, Y. (2002), 'Dynamic asset allocation under inflation', Journal of Finance 57, 1201-1238.

[12] Buiter W.H. (1997): 'Generational Accounts, Aggregate Saving and Intergenerational Distribution', in: Economica, vol. 64, pp. 605-626.

[13] Campbell, J.Y., and L.M. Viceira (2002), 'Strategic Asset Allocation, portfolio choice for long-term investors', Oxford University Press. 
[14] Campbell, J.Y., and L.M. Viceira (2005), The Term Structure of the Risk-Return Tradeoff', in: Financial Analysts Journal 61, January/February, 34-44

[15] Chapman R.J., Gordon T.J. and Speed C.A. (2001): 'Pensions, funding and risk', in: British Actuarial Journal, vol. 74, pp. 605-663.

[16] Cochrane, J.H., and M. Piazzesi (2005), 'Bond Risk Premia', American Economic Review, vol. 95(1), pages 138-160.

[17] Constantinides G.M., Donaldson J.B. and Mehra R. (2005): 'Junior must pay: pricing the implicit put in privatizing social security', in: Annals of Finance, vol 1(1), pp 1-34.

[18] Cui J., De Jong F. and Ponds E.H.M (2006): 'Intergenerational risk sharing in collective pension schemes', working paper Netspar, Tilburg University.

[19] De Jong, F. (2005), 'Pension Fund Investments and the Valuation of Liabilities under Conditional Indexation', Netspar Discussion Papers 2005 - 025, December 2005, Netspar.

[20] De Jong F. (2005): 'Valuation of pension liabilities in incomplete markets', in: Netspar Discussion Papers 2005 - 024, December 2005, Netspar.

[21] Enders W. and Lapan H. (1982): 'Social security taxation and intergenerational risk sharing ', in: International Economic Review, 23, pp 647-658.

[22] Ewijk van C., B. Kuipers , H. ter Rele, M. van de Ven \& E. Westerhout (2000): Ageing in the Netherlands, CPB, The Hague.

[23] Feldstein M.S. (2005): 'Structural reform of social security ', Journal of Economic Perspectives, vol 9(2), pp. 33-55.

[24] Gollier, C. (2005), 'Intergenerational risk sharing and risk taking of a pension fund', working paper, Toulouse.

[25] Gordon, R.H., and Varian, H.R.(1988), 'Intergenerational risk sharing', Journal of Public Economics, vol 14, pp. 1-29.

[26] Guillén M., Jorgensen P.L. and Nielsen J.P. (2006): 'Return smoothing machanisms in life and pension insurance: Path-dependent contingent claims', in: Insurance: Mathematics and Economics, vol. 38 (2006), pp. 229-252.

[27] Hári N., Koijen R. and Nijman Th. E. (2006): 'The determinants of the Money's Worth of participation in collective schemes', working paper Netspar, Tilburg University. 
[28] Hoevenaars R.P.M.M., Molenaar R.D.J., Schotman P.C., \& Steenkamp T.B.M. (2005), 'Strategic Asset Allocation with Liabilities: Beyond Stocks and Bonds', LIFE working paper, Maastricht University.

[29] Kocken T. (2006): 'Curious Contracts', PhD. Thesis, Vrije University Amsterdam

[30] Kortleve N., Nijman Th. and Ponds E.H.M. eds. (2006): 'Fair value and pension fund management', Elsevier Science.

[31] Kortleve N. and Ponds E.H.M. (2006): 'Pension deals and value-based ALM', in: Kortleve N.et al. (2006).

[32] Kotlikoff L. (2002): 'Generational policy', in: Handbook of Public Economics, vol IV, pp. 1873-1932.

[33] Krueger and Kubler (2006), "Pareto Improving Social Security Reform when FinancialMarkets are Incomplete!?", in: American Economic Reniew, vol. 96, No. 3, June 2006, pp. $737-755$

[34] Merton, R.C. (1983), 'On the role of Social Security as a Means for Efficient Risk Sharing in an Economy where human capital is not tradeable', in: Bodie Z. and Shoven J.B eds., 'Financial aspects of the United States pension system', Chicago.

[35] Munnell, A. (2006). 'Employer-sponsored plans: The Shift from Defined Benefit to Defined Contribution', in: Clark, G. L., Munnell, A., and Orszag, M. (eds): 'The Oxford Handbook of Pensions and Retirement Income', Oxford: Oxford University Press, pp. 359-380.

[36] Nijman Th. E. \& Koijen R.S.J. (2006): 'Valuation and risk management of inflationsensitive pension rights', in: Kortleve et al. (2006).

[37] Ponds E.H.M. (2003): 'Pension funds and value-based generational accounting ', in: Journal of Pension Economics and Finance, vol. 2, No. 3, pp. 295-325.

[38] Sharpe W.F. (1976): 'Corporate pension funding policy, in: Journal of Financial Economics, vol. 3, pp. 183-193.

[39] Sharpe W.F. and Tint L.G. (1990): 'Liabilities: a new approach', in: Journal of Portfolio Management, Winter.

[40] Shiller, R.J. (1999), 'Social security and institutions for intergenerational, intragenerational and international risk sharing', Carnegie-Rochester Conference Series on Public Policy, vol 50, pp. 165-204. 
[41] Smetters K. (2003): Controlling the Cost of Minimum Benefit Guarantees in Public Pension Conversions, in: NBER Working Papers 8732.

[42] Steenkamp, T.B.M. (1999), 'Contingent Claims Analysis and the Valuation of Pension Liabilities', Research Memorandum Vrije University Amsterdam

[43] Tepper I. (1981): 'Taxation and corporate pension policy', in: Journal of Finance, vol. 36, pp. $1-13$.

[44] Ziemba T.Z. (2003): 'The stochastic programming approach to asset, liability and wealth management', The Research Foundation of the Association for Investment Management and Research.

[45] Zenios S.A. \& Ziemba T.Z. (2007): 'Handbook of Asset and Liability Management', North Holland 


\section{Tables and Figures}

Table 1: Summary statistics data and scenarios

Annualized means and standard deviations are provided for the entire sample (1973:III-2005:IV) and for the generated scenarios. Variables in the VAR are 3-month euribor $\left(y^{3}\right)$, 10-year zero coupon yield $\left(y^{1} 0\right)$, price inflation $(\pi)$, MSCI world stock returns in excess of 3-month euribor $\left(x_{s}\right)$, and dividend yield $(d y)$. Stochastic scenarios are constructed by forward iterating the VAR. We transform the constant term $(c)$ to impose a different mean on the

\begin{tabular}{lrrrrr}
\hline scenarios. & $y^{3}$ & $y^{10}$ & $\pi$ & $x_{s}$ & $d y$ \\
\hline Data & & & & & \\
$\quad$ Average & 5.56 & 6.72 & 3.46 & 4.32 & 3.05 \\
stdev & 2.70 & 1.67 & 1.34 & 17.26 & 1.21 \\
\hline Scenarios & & & & & \\
$\quad$ Average & 3.50 & 4.45 & 2.00 & 5.00 & 3.30 \\
stdev & 1.80 & 1.02 & 1.00 & 21.80 & 0.73 \\
\hline \hline
\end{tabular}


Table 2: Classic ALM results for policy variants

The median, mean and standard deviation of the real funding ratio are reported at the end of the 20-year evaluation period. Mismatch risk, defined as the degree of mismatch between the pay-off structures of asset mix and liabilities, is measured by the standard deviation of the growth rate of the funding ratio (cf Leibowitz et al. 1994): $\frac{\left(R_{A}-R_{L}\right)}{1+R_{L}}$, with $R_{A}$ as return assets and $R_{L}$ as return liabilities. $\operatorname{Pw}(A<N)$ is the within probability of nominal underfunding - this is the probability of reaching a position of nominal underfunding within the 20 year evaluation period. The third group of indicators relates to indexation quality. The median, mean and standard deviation of the indexation ratio during the of 20 year period are shown. The yearly indexation ratio is measured as actual indexation over wage growth. The term $\mathrm{P}(\mathrm{IR}<100)$ indicates the frequency of less than full indexation. As an indicator of the indexation quality cumulative over the whole 20-year period, we report the probability that the cumulative value of the indexation ratio at the end of the 20-year period is less than $90 \%$ respectively less than $80 \%$ of cumulative end value of full indexation.

\begin{tabular}{|c|c|c|c|c|c|c|c|c|}
\hline & & (1) & $(2)$ & $(3)$ & (4) & $(5)$ & $(6)$ & $(7)$ \\
\hline Plan design & & NoRM & TradDB & Coll DC & Hybrid & Hybrid & Hybrid & Hybrid \\
\hline Asset mix & & $50-50$ & $50-50$ & $50-50$ & $50-50$ & 100 eq & 100 bo & $50-50$ \\
\hline Contribution policy & & fund & fund & fund & fund & fund & fund & acc \\
\hline \multicolumn{9}{|l|}{ Funding ratio } \\
\hline Median & 2025 & $103 \%$ & $106 \%$ & $107 \%$ & $105 \%$ & $112 \%$ & $95 \%$ & $118 \%$ \\
\hline Mean & 2025 & $106 \%$ & $106 \%$ & $109 \%$ & $110 \%$ & $125 \%$ & $95 \%$ & $123 \%$ \\
\hline st dev & 2025 & $26 \%$ & $19 \%$ & $16 \%$ & $22 \%$ & $52 \%$ & $5 \%$ & $26 \%$ \\
\hline Mismatch risk & av20yr & $9 \%$ & $9 \%$ & $8 \%$ & $8 \%$ & $16 \%$ & $4 \%$ & $8 \%$ \\
\hline within $\mathrm{P}(\mathrm{A}<\mathrm{N})$ & 2025 & $25 \%$ & $11 \%$ & $4 \%$ & $5 \%$ & $49 \%$ & $0 \%$ & $1 \%$ \\
\hline \multicolumn{9}{|l|}{ Contribution Rate } \\
\hline Mean & av20 yr & $17 \%$ & $18 \%$ & $17 \%$ & $17 \%$ & $14 \%$ & $22 \%$ & $22 \%$ \\
\hline jump a year & av20 yr & $0 \%$ & $3.3 \%$ & $0 \%$ & $0 \%$ & $0 \%$ & $0 \%$ & $0 \%$ \\
\hline \multicolumn{9}{|l|}{ Indexation Ratio } \\
\hline Median & av20yr & $100 \%$ & $100 \%$ & $101 \%$ & $91 \%$ & $95 \%$ & $74 \%$ & $95 \%$ \\
\hline Mean & av20yr & $100 \%$ & $100 \%$ & $106 \%$ & $79 \%$ & $72 \%$ & $74 \%$ & $86 \%$ \\
\hline st dev & av20yr & $0 \%$ & $0 \%$ & $28 \%$ & $13 \%$ & $20 \%$ & $8 \%$ & $10 \%$ \\
\hline $\mathrm{P}(\mathrm{IR}<100 \%)$ & av20yr & $0 \%$ & $0 \%$ & $62 \%$ & $56 \%$ & $40 \%$ & $90 \%$ & $43 \%$ \\
\hline $\mathrm{P}($ IRcum $<90 \%)$ & 2025 & $0 \%$ & $0 \%$ & $43 \%$ & $23 \%$ & $28 \%$ & $59 \%$ & $9 \%$ \\
\hline $\mathrm{P}($ IRcum $<80 \%)$ & 2025 & $0 \%$ & $0 \%$ & $31 \%$ & $15 \%$ & $20 \%$ & $36 \%$ & $4 \%$ \\
\hline
\end{tabular}


Table 3: Embedded options in different pension deals

\begin{tabular}{|c|c|c|c|c|c|c|c|}
\hline \multicolumn{8}{|c|}{$\begin{array}{l}\text { Option values related to pension fund residue at the end of the evaluation period as \% of } \\
\text { nominal liabilities in } 2006\end{array}$} \\
\hline & $(1)$ & $(2)$ & $(3)$ & (4) & $(5)$ & (6) & (7) \\
\hline Plan design & NoRM & Trad DB & Coll DC & Hybrid & Hybrid & Hybrid & Hybrid \\
\hline Asset mix & $50-50$ & $50-50$ & $50-50$ & $50-50$ & 100 eq & 100 bo & $50-50$ \\
\hline Contribution setting & fund & fund & fund & fund & fund & fund & acc \\
\hline Residu Option $V_{t}\left[R_{t, k}\right]$ & $1 \%$ & $17 \%$ & $21 \%$ & $20 \%$ & $12 \%$ & $29 \%$ & $28 \%$ \\
\hline Surplus Option $V_{t}\left[S_{t, k}\right]$ & $+17 \%$ & $+21 \%$ & $+23 \%$ & $+23 \%$ & $+27 \%$ & $+29 \%$ & $+29 \%$ \\
\hline Deficit Option $V_{t}\left[D_{t, k}\right]$ & $-16 \%$ & $-4 \%$ & $-2 \%$ & $-3 \%$ & $-16 \%$ & $-0 \%$ & $-1 \%$ \\
\hline
\end{tabular}

Table 4: Generational transfers due to pension reforms

\begin{tabular}{|c|c|c|c|c|c|}
\hline \multicolumn{6}{|c|}{$\begin{array}{l}\text { Size of generational value transfers } G T \text { when traditional DB plan is } \\
\text { replaced by variants. These intergenerational value transfers are ex- } \\
\text { pressed as \% of nominal liabilities } 2006\end{array}$} \\
\hline & $(3)$ & $(4)$ & $(5)$ & $(6)$ & $(7)$ \\
\hline Plan design & Coll DC & Hybrid & Hybrid & Hybrid & Hybrid \\
\hline Asset mix & $50-50$ & $50-50$ & $100 \mathrm{eq}$ & 100 bo & $50-50$ \\
\hline Contribution setting & fund & fund & fund & fund & acc \\
\hline$G T$ & $8.9 \%$ & $8.8 \%$ & $12.7 \%$ & $4.9 \%$ & $5.9 \%$ \\
\hline
\end{tabular}


Figure 1: Relative distribution of nominal liabilities in 2006 (y-axis) for various age cohorts with age at 2006 on $\mathrm{x}$-axis

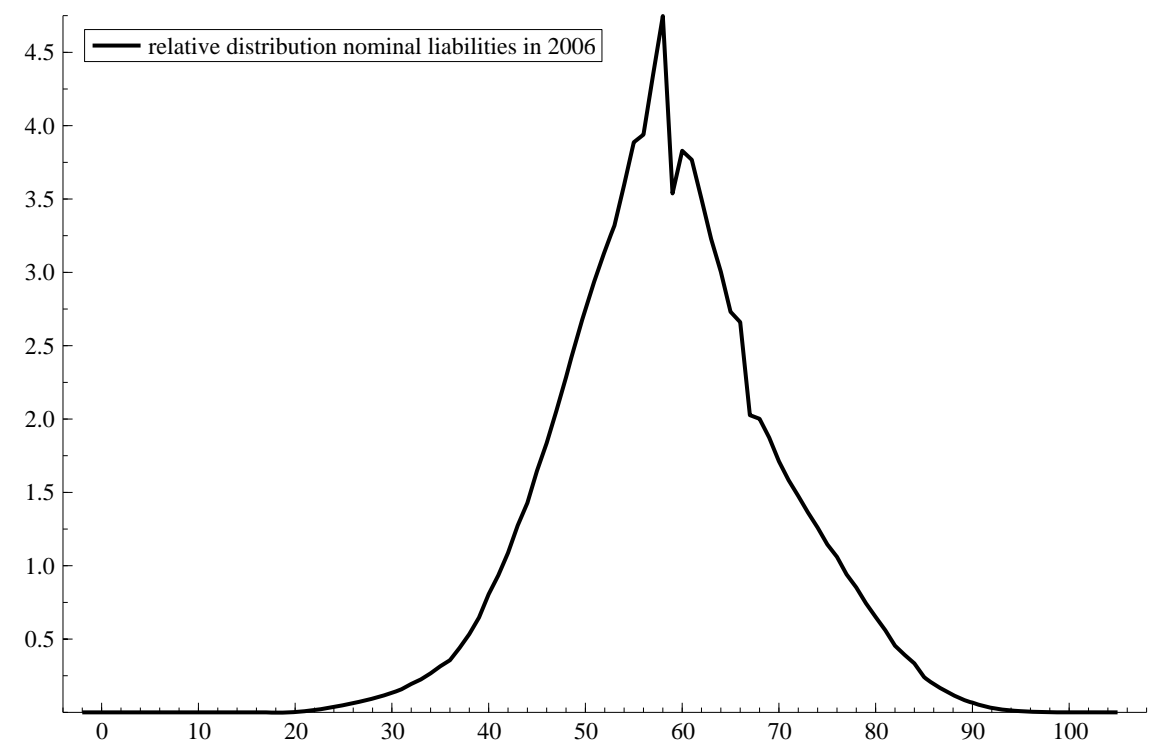


Figure 2: Different collective pension deals: pension deal 1 represents unconditional indexation and a fixed contribution rate (section 6.1.1); pension deal 2 is a traditional DB plan with unconditional indexation and a dynamic contribution rate (section 6.1.2); pension deal 3 is a hybrid plan with a dynamic indexation policy (with boundaries) and a fixed contribution rate (section 6.1.3); pension deal 4 is a collective DC with dynamic indexation and a fixed contribution rate (section 6.1.4).
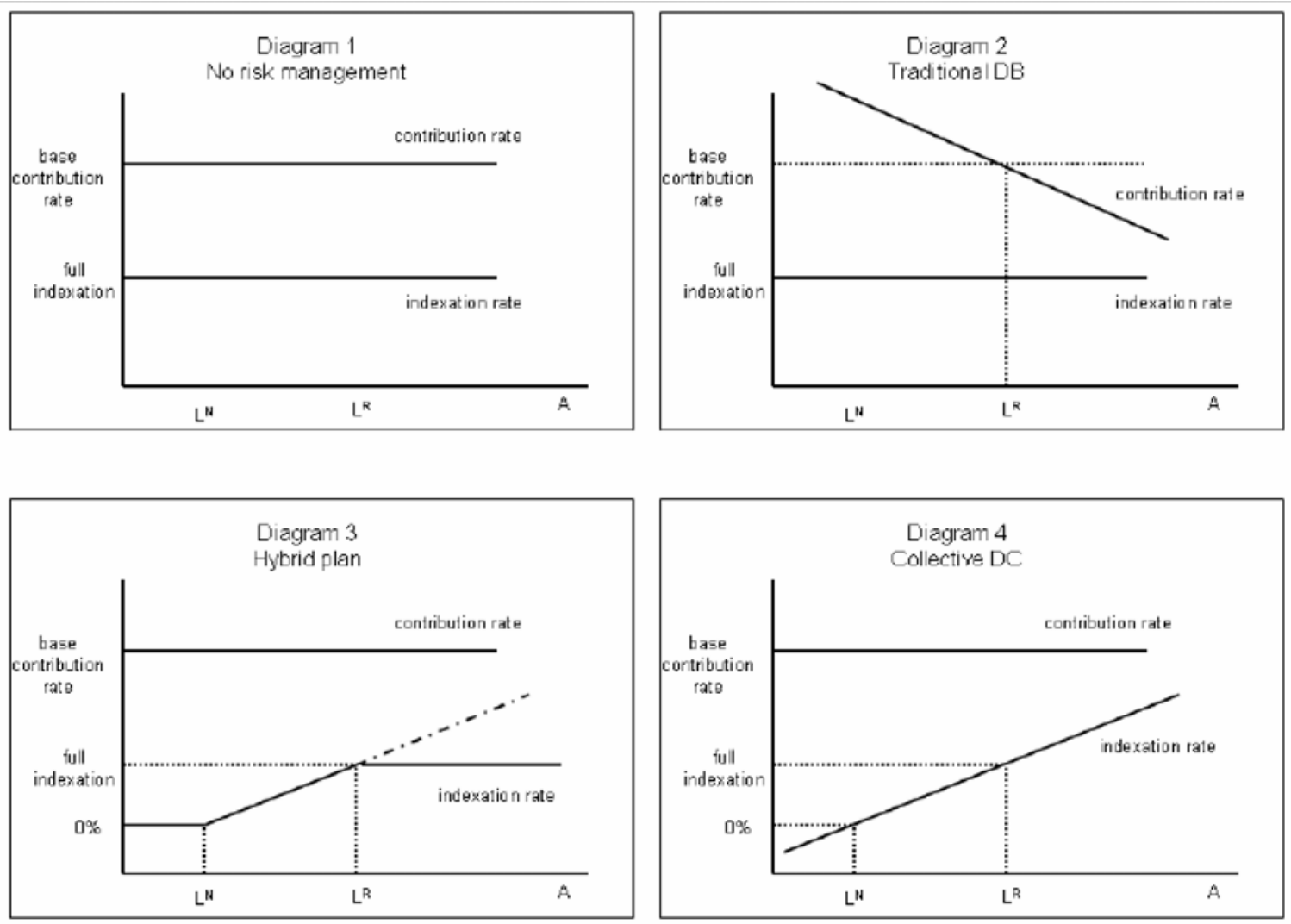
Figure 3: Generational account options for traditional DB plan and hybrid plan expressed as \% of total nominal liabilities in 2006 (y-axis) for various age cohorts with age at 2006 on $\mathrm{x}$-axis

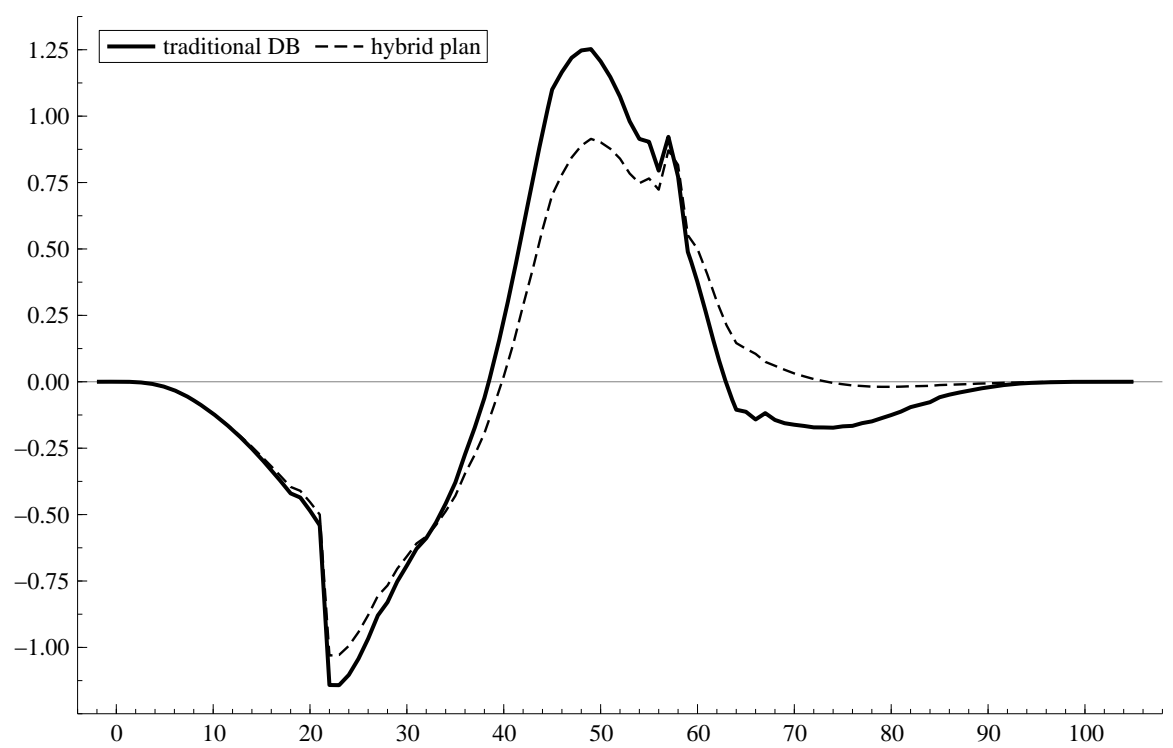

Figure 4: Generational effects when stepping over from traditional DB plan to hybrid plan expressed as \% of total nominal liabilities in 2006 (y-axis) for various age cohorts with age at 2006 on $\mathrm{x}$-axis

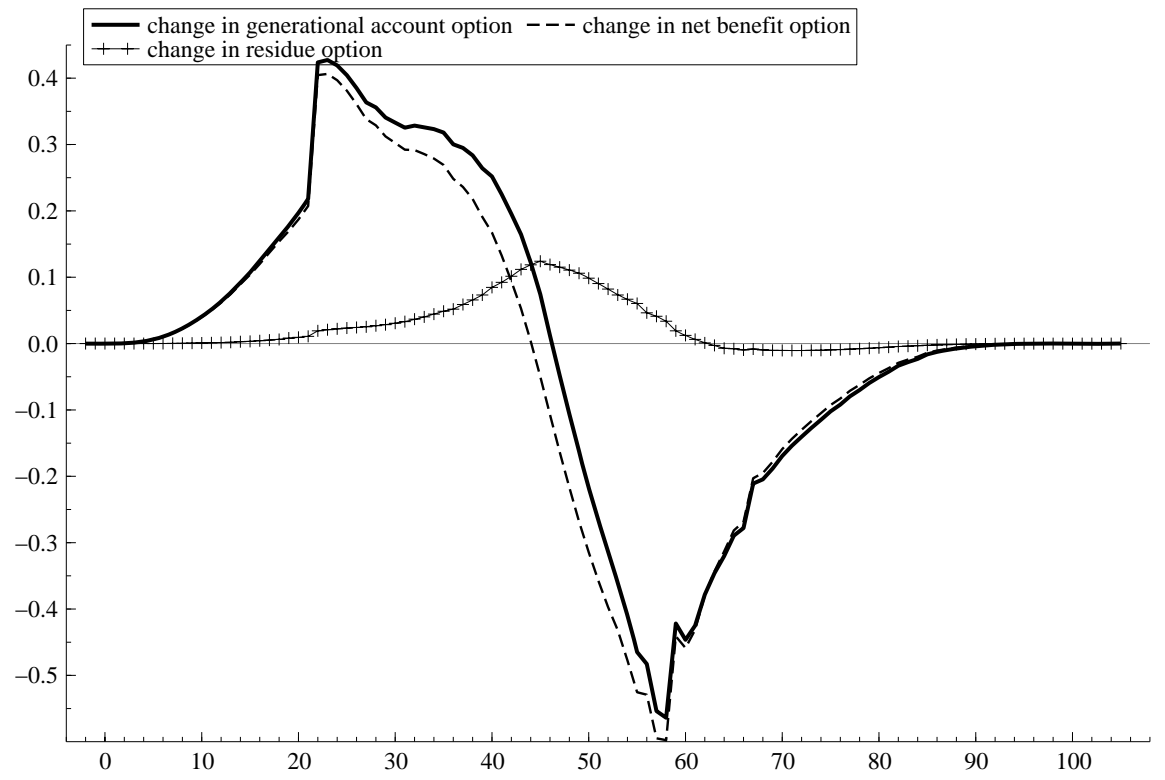


Figure 5: Generational effects when stepping over from hybrid plan to collective DC plan expressed as \% of total nominal liabilities in 2006 (y-axis) for various age cohorts with age at 2006 on $\mathrm{x}$-axis

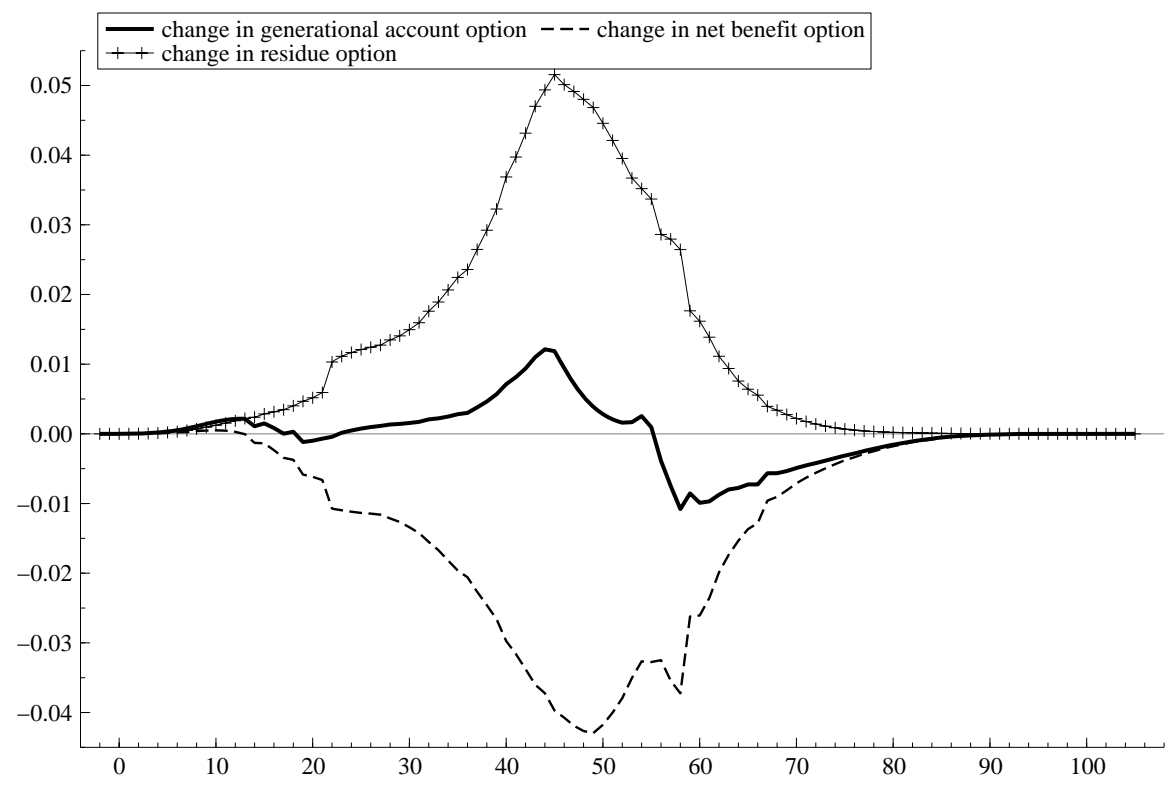

Figure 6: Generational account options for hybrid plan and different asset mixes expressed as \% of total nominal liabilities in 2006 (y-axis) for various age cohorts with age at 2006 on $\mathrm{x}$-axis

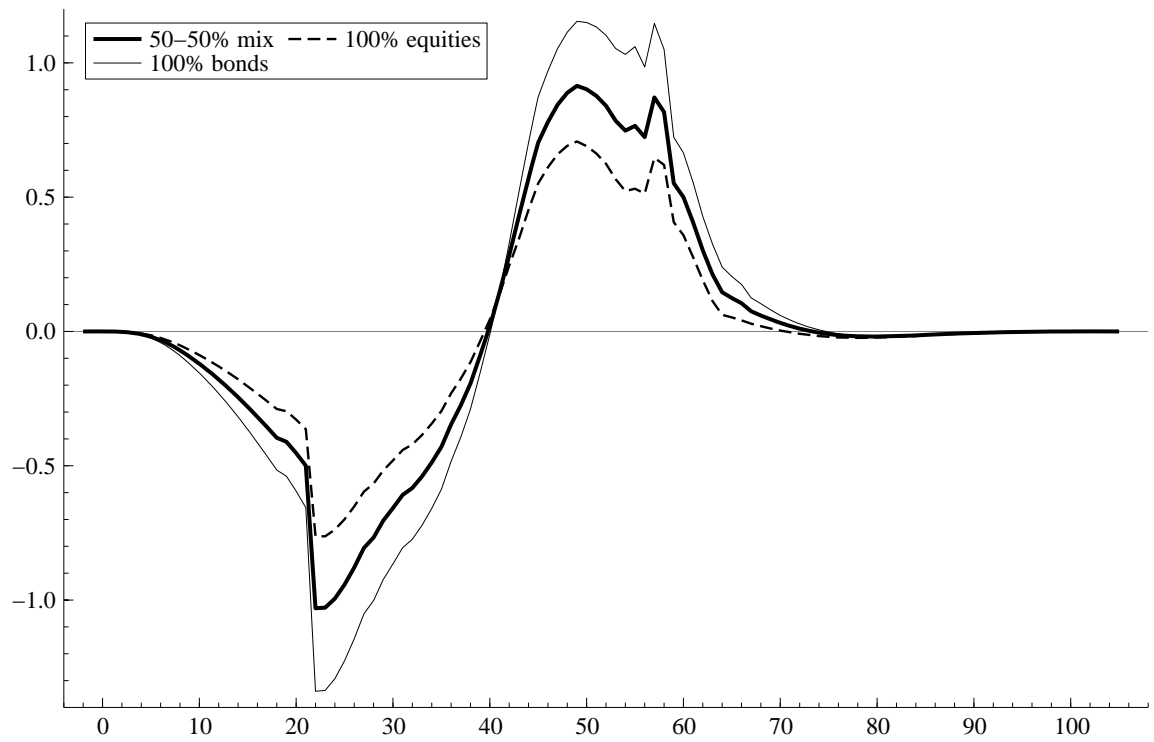


Figure 7: Generational effects when asset mix hybrid plan is changed to $100 \%$ equities expressed as \% of total nominal liabilities in 2006 (y-axis) for various age cohorts with age at 2006 on $\mathrm{x}$-axis

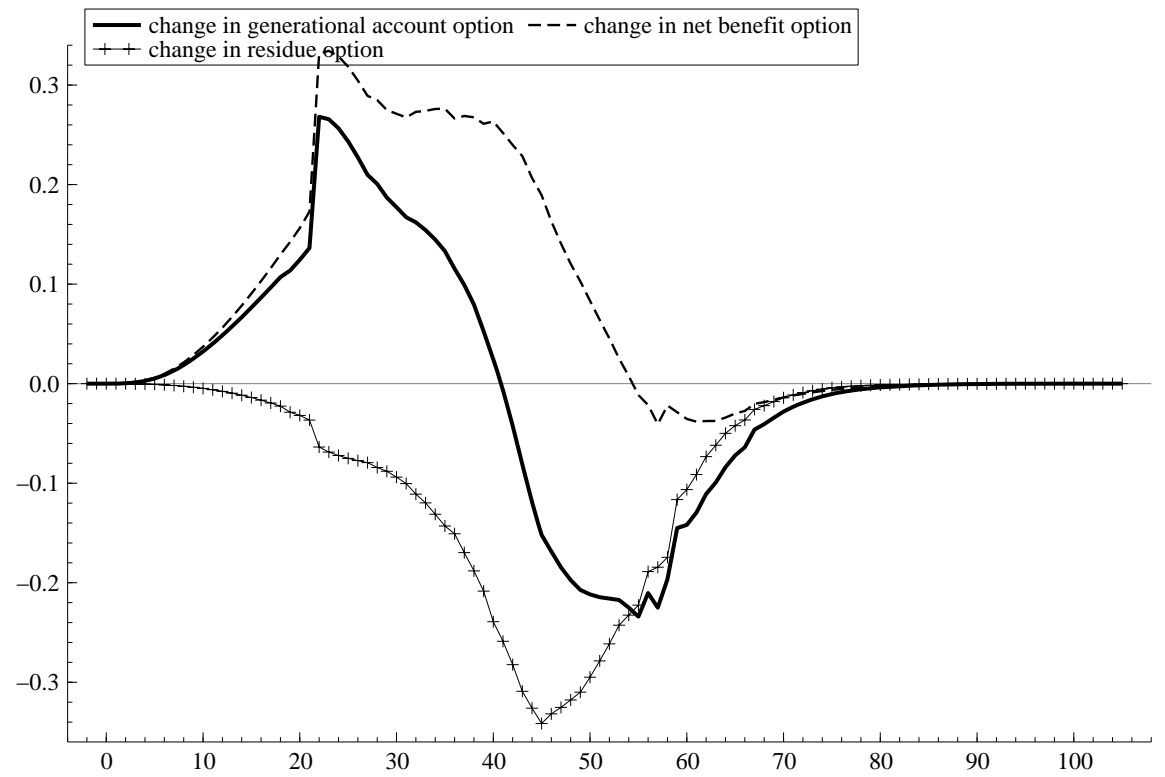

Figure 8: Generational effects when asset mix hybrid plan is changed to $100 \%$ bonds expressed as \% of total nominal liabilities in 2006 (y-axis) for various age cohorts with age at 2006 on $\mathrm{x}$-axis

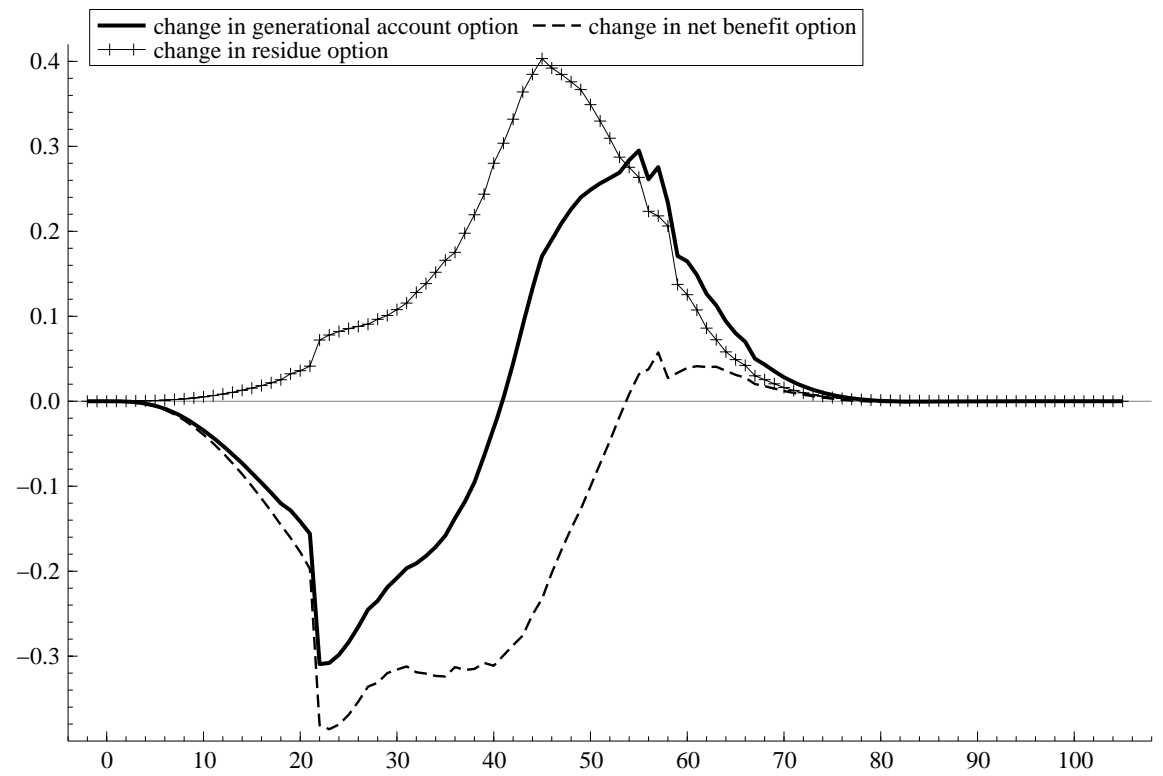


Figure 9: Generational effects when stepping over from funding to accounting in hybrid plan expressed as \% of total nominal liabilities in 2006 (y-axis) for various age cohorts with age at 2006 on $\mathrm{x}$-axis

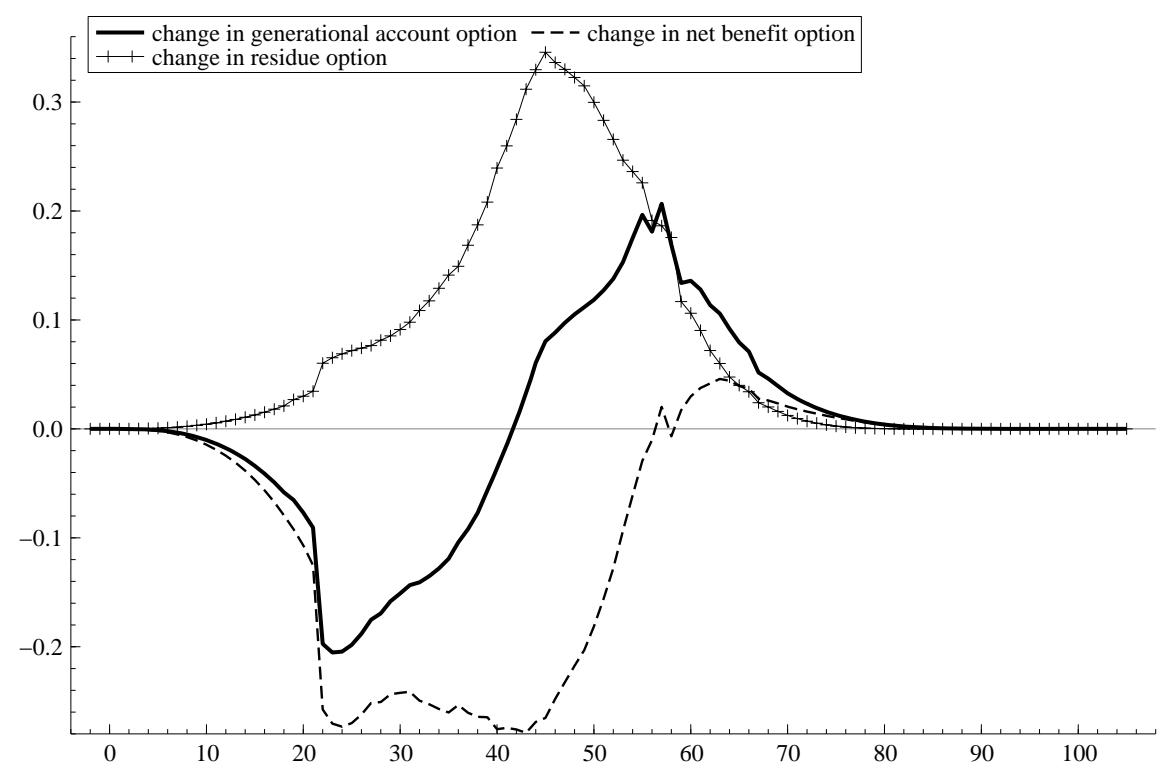

